\title{
DEVELOPMENT OF MORE-EFFICIENT GAS FLOODING APPLICABLE TO SHALLOW RESERVOIRS
}

\author{
Semi-Annual Report for the Period \\ January 1, 2001 - June 30, 2001
}

Principal Authors:

William R. Rossen, Russell T. Johns, and Gary A. Pope

Date Report Issued: January 28, 2003

Work Performed under DOE Award Number DE-AC26-99BC15208

The University of Texas at Austin

Center for Petroleum and Geosystems Engineering

1 University Station, C0300

Austin, TX 78712-1061 


\section{DISCLAIMER}

This report was prepared as an account of work sponsored by an agency of the United States Government. Neither the Unites States Government nor any agency thereof, nor any of their employees, makes any warranty, express or implied, or assumes any legal liability or responsibility for the accuracy, completeness, or usefulness of any information, apparatus, product, or process disclosed, or represents that its use would not infringe privately owned rights. Reference herein to any specific commercial product, process, or service by trade name, trademark, manufacturer, or otherwise does not necessarily constitute or imply its endorsement, recommendation, or favoring by the United States Government or any agency thereof. The views and opinions of authors expressed herein do not necessarily state or reflect those of the United States Government or any agency thereof. 


\title{
DEVELOPMENT OF MORE-EFFICIENT GAS FLOODING APPLICABLE TO SHALLOW RESERVOIRS
}

\author{
Contract No. DE-AC26-99BC15208 \\ The University of Texas at Austin \\ 1 University Station, C0300 \\ Austin, TX 78712-1061 \\ Contract Date: July 9, 1999 \\ Anticipated Completion: July 8, 2002
}

\section{ABSTRACT:}

The objective of this research is to widen the applicability of gas flooding to shallow oil reservoirs by reducing the pressure required for miscibility using gas enrichment and increasing sweep efficiency with foam. Task 1 examines the potential for improved oil recovery with enriched gases. Subtask 1.1 examines the effect of dispersion processes on oil recovery and the extent of enrichment needed in the presence of dispersion. Subtask 1.2 develops a fast, efficient method to predict the extent of enrichment needed for crude oils at a given pressure. Task 2 develops improved foam processes to increase sweep efficiency in gas flooding. Subtask 2.1 comprises mechanistic experimental studies of foams with $\mathrm{N}_{2}$ gas. Subtask 2.2 conducts experiments with $\mathrm{CO}_{2}$ foam. Subtask 2.3 develops and applies a simulator for foam processes in field application.

Regarding Task 1, several key results are described in this report relating to subtask 1.1. In particular, we show how for slimtube experiments, oil recoveries do not increase significantly with enrichments greater than the MME. For field projects, however, the optimum enrichment required to maximize recovery on a pattern scale may be different from the MME. The optimum enrichment is likely the result of greater mixing in reservoirs than in slimtubes. In addition, 2-D effects such as channeling, gravity tonguing, and crossflow can impact the enrichment selected. We also show the interplay between various mixing mechanisms, enrichment level, and numerical dispersion. The mixing mechanisms examined are mechanical dispersion, gravity crossflow, and viscous crossflow. UTCOMP is used to evaluate the effect of these mechanisms on recovery for different grid refinements, reservoir heterogeneities, injection boundary conditions, relative permeabilities, and numerical weighting methods including higher-order methods. For all simulations, the reservoir fluid used is a twelve-component oil displaced by gases enriched above the MME.

The results for subtask 1.1 show that for 1-D enriched-gas floods, the recovery difference between displacements above the MME and those at or near the MME increases significantly with dispersion. The trend, however, is not monotonic and shows a maximum at a dispersivity (mixing level) of about $4 \mathrm{ft}$. The trend is independent of relative permeabilities and gas trapping for dispersivities less than about $4 \mathrm{ft}$. For 2-D enriched gas floods with slug injection, the difference in recovery generally increases as 
dispersion and crossflow increase. The magnitude of the recovery differences is less than observed for the 1-D displacements. Recovery differences for 2-D models are highly dependent on relative permeabilities and gas trapping. For water alternating gas (WAG) injection, the differences in recovery increase slightly as dispersion decreases. That is, the recovery difference is significantly greater with WAG at low levels of dispersion than with slug injection. For the cases examined, the magnitude of recovery difference varies from about 1 to 8 percent of the original oil-in-place (OOIP).

Regarding Task 2, three results are described in this report: 1) New experiments with $\mathrm{N}_{2}$ foam examined the mobility of liquid injected following foam in alternating-slug (SAG) foam processes. These experiments were conducted in parallel with a simulation study of foam for acid diversion in well stimulation. The new experiments qualitatively confirm several of the trends predicted by simulation. 2) A literature study finds that the two steady-state foam-flow regimes seen with a wide variety of $\mathrm{N}_{2}$ foams also appears in many studies of $\mathrm{CO}_{2}$ foams, if the data are replotted in a format that makes these regimes clear. A new experimental study of dense $\mathrm{CO}_{2}$ foam here failed to reproduce these trends, however; the reason remains under investigation. 3) A number of published foam models were examined in terms of the two foam-flow regimes and using fractional-flow theory. At least two of the foam models predict the two foam-flow regimes. Fractional-flow theory predicts that large-scale simulation using one of the models would lead to numerical artifacts, however. 
TABLE OF CONTENTS

$\begin{array}{lr}\text { ABSTRACT } & \text { Page } 3 \\ \text { OBJECTIVES } & \text { Page } 6 \\ \text { RESULTS AND DISCUSSION } & \text { Page } 6 \\ \text { Task } 1 & \text { Page } 6 \\ \text { Task } 2 & \text { Page } 8 \\ \quad \text { Subtask } 2.1 & \text { Page } 8 \\ \text { Subtask } 2.2 & \text { Page } 9 \\ \text { Subtask } 2.3 & \text { Page } 11 \\ \text { REFERENCES } & \text { Page } 12 \\ \text { FIGURES } & \end{array}$




\section{OBJECTIVES}

The objective of this research is to widen the applicability of gas flooding to shallow oil reservoirs by reducing the pressure required for miscibility using gas enrichment and increasing sweep efficiency with foam. Task 1 examines the potential for improved oil recovery with enriched gases. Subtask 1.1 examines the effect of dispersion processes on oil recovery and the extent of enrichment needed in the presence of dispersion. Subtask 1.2 develops a fast, efficient method to predict the extent of enrichment needed for crude oils at a given pressure. Task 2 develops improved foam processes to increase sweep efficiency in gas flooding. Subtask 2.1 comprises mechanistic experimental studies of foams with $\mathrm{N}_{2}$ gas. Subtask 2.2 conducts experiments with $\mathrm{CO}_{2}$ foam. Subtask 2.3 develops and applies a simulator for foam processes in field application.

\section{SUMMARY}

\section{TASK 1: REDUCE MMP WITH GAS ENRICHMENT}

Both slug and WAG injection are presented in this report to consider how overenrichment of gas (above the MME) would affect oil recovery in shallow gas reservoirs (Solano et al. 2001, 2000). For slug injection, 0.20 HCPV of gas is injected followed by a 1.0 HCPV waterflood. For WAG, $0.3 \mathrm{HCPV}$ of water is injected followed by $0.2 \mathrm{HCPV}$ gas and $0.2 \mathrm{HCPV}$ of water in six alternating cycles. Each cycle therefore consists of $0.033 \mathrm{HCPV}$ gas and $0.033 \mathrm{HCPV}$ water injection. The six alternating cycles are followed by a $0.5 \mathrm{HCPV}$ waterflood. The relative permeabilities were modified to account for gas trapping during a waterflood. Total injection of fluids for either WAG or slug injection is 1.2 HCPV. Results are presented for six different reservoir models.

1-D homogeneous, slug injection. In this example, oil is displaced in a 1-D horizontal flood (x-direction) by a $0.2 \mathrm{HCPV}$ slug of enriched-gas. The slug of enrichedgas is then driven by water until 1.2 HCPV of total fluid is injected. Figure 1.1 gives the recovery for two levels of enrichment as a function of dispersion. Dispersion is varied by using 40,60, 100, 200, and 500 grid blocks. To reduce dispersion further, the same simulations were conducted using two-point and three-point upstream weighting. These results are also presented in Fig. 1.1. For one-point upstream weighting, the range of dispersivity varies from approximately $1.0 \mathrm{ft}$ (500 grid blocks) to $12.5 \mathrm{ft}$ (40 grid blocks).

As expected, recovery increases monotonically as dispersion decreases. That is, recovery increases as the grid-block size is reduced or when higher-order methods are used. For example, for 65 percent enrichment and one-point weighting, oil recovery increases by 10 percent from a dispersivity of $12.5 \mathrm{ft}$ to $1.0 \mathrm{ft}$. Figure 1.1 also shows that recovery extrapolated to zero dispersion approaches a value significantly less than 1.0, i.e. calculated analytical to be about 0.75 . The reduced recovery at zero dispersion occurs because all of the enriched-gas is trapped prior to complete displacement of the oil (maximum trapped gas is set at 0.29). After the injected gas is trapped, oil is displaced only by water, thus leaving behind significant oil.

Figure 1.2 presents the difference in recovery between displacements at 85 and 65 percent enrichment. The difference generally increases with greater dispersion and with the use of lower-order methods. Additionally, the extrapolated value of recovery difference is zero when dispersion is zero. The low-dispersion limit is as expected, 
because recovery should be independent of enrichment for dispersion-free 1-D miscible flow, i.e. method of characteristics limit. The recovery curve for single-point weighting, however, shows an "anomalous" response, in that a maximum in recovery difference occurs at a dispersivity value of $5.1 \mathrm{ft}$. The maximum occurs because recovery with 65 percent enrichment has a different sensitivity to dispersion than when 85 percent enrichment is used. Johns et al. (2000, 1999) showed that the sensitivity for 1-D displacements with enrichments above the MME depends on the phase behavior, i.e. primarily the compositional direction of the tie lines. The two and three-point weighting curves do not show a maximum because they are obtained at estimated dispersivities less than $5.1 \mathrm{ft}$.

Figure 1.3 illustrates more clearly the trend in recovery difference by plotting all 1-D simulations and a few additional points at larger dispersivities on the same dispersivity scale. (The effective dispersivities for two-point and three-point weighting are calculated from work presented in previous reports). Although the dispersivities are only approximate, Figure 1.3 shows excellent agreement between all weighting methods. The difference in recovery peaks at eight percent near a dispersivity of $4 \mathrm{ft}$. For the lowdispersivity range (below $4 \mathrm{ft}$ ), the recovery difference is very sensitive to dispersion. Above $4 \mathrm{ft}$, the difference in recovery is not as sensitive to dispersion, but does decrease asymptotically to the high-dispersion limit at about 1.4 percent.

The results also indicate that for slimtube displacements where dispersivity is very small, recovery differences for enrichments beyond the MME are small. For greater levels of dispersivity found in reservoirs (i.e. $0.1-2 \mathrm{ft}$ ), however, recovery differences are very sensitive to dispersion and could be significant.

2-D homogeneous slug injection. This example is similar to the one above, except that the model is 2-D. Thus, dispersion, viscous crossflow, and gravity crossflow can now affect recoveries. Ten grid blocks are used to refine the model in the z-direction. Because the vertical to horizontal permeability ratio is 1.0 , a gravity tongue develops at the top of the reservoir and a water tongue moves downward in the reservoir.

The recoveries for the 2-D model are lower than those in the 1-D model because of viscous and gravity crossflow (see Fig. 1.4). That is, recoveries are lower because of reduced sweep efficiency and greater overall mixing of gas with contacted oil. Generally, recoveries tend to increase as dispersion is reduced, although the behavior is not always monotonic. Hence, it is difficult to extrapolate recoveries to zero dispersion.

A plot of recovery differences shows a more distinct trend with dispersion than do the recoveries (see Fig. 1.5). There is a peak in the recovery difference of about 5 percent OOIP. The recovery differences generally decrease as dispersion approaches zero, although that limit is uncertain. This behavior is in some degree similar to the result obtained in the 1-D model because the gas tongue at the top of the reservoir is quasi onedimensional. The maximum recovery difference is less than the 1-D cases because the increase in displacement efficiency with enrichment above the MME is limited to the swept region of the gas tongue.

The trend shown in Fig. 1.5 for the 2-D floods cannot be collapsed to one curve as was done for the 1-D cases. This is because both longitudinal and transverse dispersion are present in 2-D displacements.

2-D reservoir w/ discontinuous shales, slug injection. We now consider the effect of various heterogeneities on recovery. Figure 1.6 shows the location of three discontinuous shales in the model. Except for the addition of shales, these displacements occur under the same conditions as for the above reservoir models. 
In this example, recoveries generally increase monotonically as grid-block size decreases. Recoveries are about 5 percent OOIP larger than for the 2-D homogeneous model primarily because the shales restrict vertical crossflow and allow for better sweep. Figure 1.7 shows the differences in recovery between the 85 and 65 percent solvents. The recovery differences are generally greater and more sensitive to dispersion than for the case without shales. The recovery differences for each weighting method also clearly show a maximum, although they exhibit different trends. The differences in the trends are again probably related to differences in numerical dispersion in the z-direction with each weighting method.

2-D reservoir $\boldsymbol{w} /$ discontinuous shales, $\boldsymbol{W A G}$. This example considers the effect of WAG on recovery differences between the 85 and 65 percent solvents. The same discontinuous shale layers as above are used. With WAG instead of slug injection, the difference in recoveries increases somewhat as dispersion decreases (see Fig. 1.8) This trend is opposite of those seen in the previous five cases. In addition, the increase is more significant when the higher-order methods are used. For example, for two-point weighting, the increase in recovery differences is about 2 percent OOIP from 40 to 100 grid blocks. Such a result suggests that crossflow is very important when WAG is used, especially at low values of dispersivity. WAG apparently causes significant mixing independent of the grid-block size used.

2-D layered model, $\boldsymbol{W A G}$. Here the model consists of ten equal-thickness layers of different permeability. The values of permeability are 5, 50, 30, 100, 50, 165, 50, 10, 100 , and 40 md from the top of the reservoir to the bottom. The vertical to horizontal permeability ratio is 1.0 for all layers, which allows for maximum crossflow. WAG recoveries are smaller than for previous WAG case by about 3 to 4 percent OOIP, primarily because of decreased sweep.

The recovery differences for this example reservoir increase as dispersion decreases, although the magnitude of the differences are about half of those for the discontinuous case (compare Fig. 1.9 to Fig. 1.8). The increase in recovery difference is about 1 percent OOIP for the range of grid-block sizes examined.

2-D layered model, slug injection. This case illustrates how channeling might significantly affect the recoveries with enrichment above the MME. The model is the same as the layered model above, except that slug injection is used instead of WAG. Figure 1.10 shows that the recovery differences with slug injection decrease substantially to near zero when three-point weighting is used. The decrease is caused by gas channeling through the largest-permeability layer located in the center of the model (see Fig. 1.11). Channeling occurs only when the 85 percent enriched gas and three-point weighting is used because the denser gas reduces gravity crossflow to the top lower permeability layers. The three-point weighting method also reduces vertical mixing of the fluids, which enhances the potential for channeling. With WAG, gas channeling does not occur because significant vertical mixing is present.

\section{TASK 2: INCREASE SWEEP EFFICIENCY WITH FOAM SUBTASK 2.1: MECHANISTIC EXPERIMENTS}

The mobility of liquid injected after foam is important to liquid injectivity in foam processes in which liquid and gas are injected in alternating slugs (surfactant-alternatinggas, or SAG, injection). In the otherwise-successful SAG foam field trial in the Snorre field (Martinssen and Vassenden, 1999), low liquid injectivity caused fracturing of the injection well and loss of most of the injected surfactant in the second and third liquid 
slugs. Low liquid mobility after foam injection is also crucial to the success of foam-acid diversion processes (Kibodeaux et al., 1994).

Previous experiments on liquid injection after foam had been conducted in conjunction with foam-acid diversion for well stimulation (Kibodeaux et al., 1994; Rossen and Wang, 1999). New experiments were conducted in parallel with a simulation study (Cheng et al., 2002). Simulation of the process had concluded that much of the gas trapped in foam remains trapped during liquid injection, and that this trapped gas is the key to injectivity of liquid after foam. There is a transition period between foam injection and liquid-only injection in which a portion of the gas escapes. The final steady-state liquid mobility depends on the amount of gas that escapes during this period. In addition to the complexities of foam, laboratory experiments must also cope with effects of gas expansion as pressure in the core declines during this process. They must also cope with an experimental artifact due to the existence of a dead volume in the apparatus - a region upstream of the core containing the foam generator, tubing, fittings, etc. - that can affect behavior in the core. Simulations had estimated the effects of these factors, but needed confirmation.

New experiments were conducted with care taken to exclude the dead volume. The new experiments agreed with the simulations in a qualitative way. The simulations and experiments agree that gas compressibility greatly lengthens the transition period in the laboratory; that higher injection rates shorten the transition period; and that the effect of a shut-in period between foam and liquid injection depends on the length of the shut-in period. These results help guide the simulation of liquid injection during SAG foam processes.

\section{SUBTASK 2.2: $\mathrm{CO}_{2}$ FOAM EXPERIMENTS}

A major goal of this research is to determine whether the large body of research on $\mathrm{N}_{2}$ foams applies also to foams made with supercritical $\mathrm{CO}_{2}$.

A number of studies of foams made with $\mathrm{N}_{2}$ gas find that at steady state foam exists in two regimes depending on injected gas volume fraction, i.e. foam quality $f_{g}$ (Alvarez et al., 2001; Rong, 2002). Fig. 2.1 illustrates one such case. In the high-quality regime (upper-let portion of figure), pressure gradient is nearly independent of gas injection rate. In this regime foam properties are controlled by bubble coalescence and capillary pressure, and bubble sizes change drastically as a function of gas-injection rate. Foam mobility can be shear-thinning, Newtonian or shear-thickening at fixed foam quality in this regime. In the low-quality regime (lower-right portion of figure), pressure gradient is nearly independent of liquid injection rate. In this regime, it is thought, bubble size is fixed and foam properties are controlled by bubble trapping and mobilization. Rheology in the low-quality regime is shear-thinning, often strongly so. Theory suggests that the high-quality regime should be more sensitive to factors that affect foam stability and to permeability than the low-quality regime, and experiments bear this out in part (Rong, 2002). The foam quality $\mathrm{f}_{\mathrm{g}}{ }^{*}$ that separates the high-quality and low-quality regimes depends on surfactant formulation, porous medium, and any other factor that affects the stability of lamellae in the porous medium.

This pattern of two strong-foam regimes is observed with a variety of surfactant formulations and gases, in porous media varying from consolidated cores to sandpacks and beadpacks, and over a wide range of injection rates (Alvarez et al., 2001; Rong, 2002). The difference between these two regimes is important, because their rheology and 
ability to divert flow between layers differing in permeability is very different. But it was not clear if the two regimes apply to foams made with $\mathrm{CO}_{2}$ at high pressure.

A first step in this study was a reinterpretation of earlier published data on foams made with dense $\mathrm{CO}_{2}$. The pattern of either the high-quality regime or the low-quality regime was observed in many of the data (Figs. 2.2 to 2.9). But none of the data sets clearly showed both regimes for the same surfactant formulation.

Therefore an experimental was undertaken specifically to observe to identify the two steady-state foam-flow regimes with dense $\mathrm{CO}_{2}$ in a Berea core. (The experiments were conducted at room temperature, a little below the critical temperature of $\mathrm{CO}_{2}$, so this was not strictly supercritical $\mathrm{CO}_{2}$.)

Details of the experimental apparatus and method are described in Dong's MS Thesis. Room-temperature experiments were conducted with solutions of 0.25 and 0.8 wt $\%$ Chaser CD1045 surfactant. The results are shown in Figs. 2.10 and 2.11. They do not fit the pattern of the two flow regimes seen in other experiments. Rather than contours of pressure gradient that are vertical or horizontal, with a transition region where contours slope down and to the right, these contours slope up and to the right. One intriguing implication of the data is that at fixed gas injection rate pressure gradient declines substantially as liquid injection rate increases.

One possible reason why these data do not show the same two distinct regimes as $\mathrm{N}_{2}$ foam may lie in the fact that $\mathrm{CO}_{2}$ is very different from $\mathrm{N}_{2}$ at high pressure. It behaves more like a liquid than a gas at the experimental conditions of this study. Also the interfacial tension between $\mathrm{CO}_{2}$ and most surfactant solutions is much lower than that between $\mathrm{N}_{2}$ and surfactants. This would not explain the differences with other $\mathrm{CO}_{2}$ foams in Figs. 2.2 to 2.9, however.

As shown in Figs. 2.2 to 2.9, other experimental data show the two flow regimes apparently for $\mathrm{CO}_{2}$ foam at those experimental conditions. The failure to observe this behavior in our experiments may be due to the following reasons. First, the flow-rate range in this experiment is narrower than that in the earlier studies due to the limitation of our pumps. Second, the choice of surfactant type and concentration may affect our results. Third, most experiments in Fig. 2.2 to 2.9 were done at elevated temperature. Pressure and temperature should not cause much difference to the flow behavior if $\mathrm{CO}_{2}$ is in a supercritical state. But they do affect interfacial tension to some extent.

There were some other reasons for caution in interpreting the data.

First, in our experiments it took a long time to reach steady state in each new core. Steady state was reached much faster if a core had been previously flushed with surfactant solution and $\mathrm{CO}_{2}$. The mixture of $\mathrm{CO}_{2}$ and surfactant solution appeared to form a weak acid inside the core and interacted with some minerals of the core. This process evidently took some time to reach a steady state

Second, the permeability of a core decreased substantially over about two months of experiments, while there was little change in porosity.

Third, cycles of pressure-drop fluctuation were recorded when foam quality was high. This sort of cycling was observed by Khatib et al. (1988) in their original study of the limiting capillary pressure. In these cases, the average pressure drop in the cycle is used in constructing Figs. 2.10 and 2.11.

Finally, effluent fluids were reddish-brown, suggesting dissolution of either mineral components in the Berea sandstone or in the apparatus itself. It is conceivable that dissolved minerals may also have affected foaming of the surfactant formulation. Out of concern that the results here may reflect mineralogical interactions with the Berea 
sandstone, we decided to extend the study to foam in sandpacks. Results of that study will be reported in future reports.

\section{SUBTASK 2.3: Simulation DEVELOPMENT AND APPLICATION}

In parallel with our simulation work, we have analyzed foam models using fractional-flow theory and in terms of the two foam-flow regimes discussed above. Many field applications of foam involve SAG injection. Fractional-flow theory suggests that such a process may fail, with complete collapse of foam during gas injection, if the fractional-flow curve for foam has a sharp corner at extremely low fractional flow of water. As discussed above, the two foam-flow regimes are important because rheology is very different between them, and as is the ability of foam to divert flow between geological layers differing in permeability.

Dong's thesis (2001), recently completed, reports a study of a number of foam simulation models in the published literature. Two examples are shown here. The model of Vassenden and Holt (2000), developed for foam applications in the Snorre field, explicitly accounts for the two foam-flow regimes. Therefore, it is not surprising that at steady state this model reproduces the two regimes (Fig. 2.12). The fractional-flow curve for foam (Fig. 2.13) has a surprising kink at low water fractional-flow $f_{w}$, but because it is rounded at the lowest $f_{w}$ values, fractional-flow theory predicts a successful SAG process if foam obeys this model.

The local-steady-state model of Bertin (2000) includes both a minimum bubble size, thought to be the origin of the low-quality regime (Alvarez et al., 2001), and foam collapse at a limiting capillary pressure, the mechanism of the high-quality regime. Therefore one would expect to observe both flow regimes at steady-state with this model, and one does, as shown in Fig. 2.14. The model predicts a corner in the fractional-flow curve at very low $f_{w}$ (Fig. 2.15) however, which suggests that a simulation with the model would have foam collapse in a narrow front at the leading edge of the gas bank. Bertin's published simulations encountered fluctuations in flow between layers, suggesting a numerical artifact created by foam strengthening and collapsing within a front one grid block wide. Attempts to reproduce the simulation result using fractional-flow theory failed, however. Evidently capillary-pressure effects, assumed to be unimportant in fractional-flow theory, were important in this simulation of a core-scale displacement. 


\section{REFERENCES}

Alvarez, J.M., Rivas, H., and Rossen, W.R.: "A Unified Model for Steady-State Foam Behavior at High and Low Foam Qualities," SPE J (Sept. 2001), 325-333.

Bertin, H. J.: "Foam Diversion Modeling Using a Bubble-Population Correlation," paper SPE 59366 presented at the 2000 SPE/DOE Improved Oil Recovery Symposium, Tulsa, OK, Apr. 3-5, 2000.

Chang, S. H. and Grigg, R. B.: "Effects of Foam Quality and Flow Rate on CO2 -Foam Behavior at Reservoir Conditions," SPE 39679 presented at the 1998 SPE/DOE Improved Oil Recovery Symposium, Tulsa, OK, Apr. 19-22.

Cheng, L., Kam, S. I., Delshad, M., and Rossen, W. R.: "Simulation of Dynamic FoamAcid Diversion Processes," Cheng, L., Kam, S.I., Delshad, M. and Rossen, W.R., "Simulation of Dynamic Foam-Acid Diversion Processes," SPE Journal (Sept. 2002), 316-324.

Dong, Y.: "Experimental Study of $\mathrm{CO}_{2}$ Foam Flow in Porous Media and Application of Fractional-Flow Method to Foam Flow," MS Thesis, , The University of Texas at Austin, 2001.

Heller, J. P., Lien, C. L., and Kuntamukkula, M. S.: "Foamlike Dispersions for Mobility Control in $\mathrm{CO}_{2}$ Floods," SPE J, August 1985.

Johns, R.T., Sah, P., and Subramanian, S., Effect of gas enrichment above the MME on oil recovery in enriched-gas floods, SPEJ, 5(3), September, pp. 331-338, 2000.

Johns, R.T., Sah, P., and Solano, R., Effect of dispersion on local displacement efficiency for multicomponent enriched-gas floods above the MME, SPE International Oil \& Gas Conference and Exhibition in China, SPE No. 64725, November 7 - 10, Beijing, China, 2000.

Johns, R.T., Sah, P., and Subramanian, S., Effect of gas enrichment above the MME on oil recovery in enriched-gas floods, SPE Annual Tech. Conf. And Exhib., SPE No. 56826, October 3-6, pp. 487-496, 1999.

Khatib, Z. I., Hirasaki, G. J., and Falls, A. H.: "Effects of Capillary Pressure on Coalescence and Phase Mobilities in Foam Flowing Through Porous Medium," SPE Reservoir Eng. (Aug. 1988) 3,919-926.

Kibodeaux, K.R., Zeilinger, S.C. and Rossen, W.R.: "Sensitivity Study of Foam Diversion Processes for Matrix Acidization," paper SPE 28550 presented at the 69th Annual Technical Conference held in New Orleans, LA, Sept. 26-28, 1994.

Lee, H. O. and Heller, J. P.: "Laboratory Measurements of $\mathrm{CO}_{2}$-Foam Mobility," SPE Reservoir Eng., May 1990.

Lee, H. O. and Heller, J. P.: "Mobility of $\mathrm{CO}_{2}$ and Surfactant Adsorption in Porous Rocks," Oil Field Chemistry, 1989.

Martinsen, H. A., and Vassenden, F.: "Foam-Assisted Water Alternating Gas (FAWAG) Process on Snorre," presented at the 10th European IOR Symposium, Brighton, UK, Aug. 18-20, 1999.

Rong, J. G.: "Experimental Evaluation of Foam in Environmental Remediation," $\mathrm{PhD}$ dissertation, The University of Texas at Austin, 2002.

Rossen, W.R., and Wang, M.-W.: "Modeling Foams for Matrix Acid Diversion," SPE J. (June 1999), 92-100.

Solano, R., Johns, R.T., and Lake, L.W., Impact of reservoir mixing on recovery in enriched-gas drives above the minimum miscibility enrichment, SPEREE, 4(5), October, pp. 358-365, 2001. 
Solano, R., Johns, R.T., and Lake, L.W., Impact of reservoir mixing on recovery in enriched-gas drives above the minimum miscibility enrichment, $S P E / D O E$ Symposium on Improved Oil Recovery, SPE No. 59339, Tulsa, OK, proceedings on CDROM only (no page numbers), April 3-5, 2000.

Vassenden, F. and Holt, T.: "Experimental Foundation for Relative Permeability Modeling of Foam," SPE Reservoir Eval. \& Eng., April 2000.

Yaghoobi, H. and Heller, J. P.: "Laboratory Investigation of Parameters Affecting CO2 Foam Mobility in Sandstone at Reservoir Conditions," paper SPE 29168 presented at the 1994 Eastern Regional Conference \& Exhibition held in Charleston, WV. U. S. A., 8-10 November 1994 


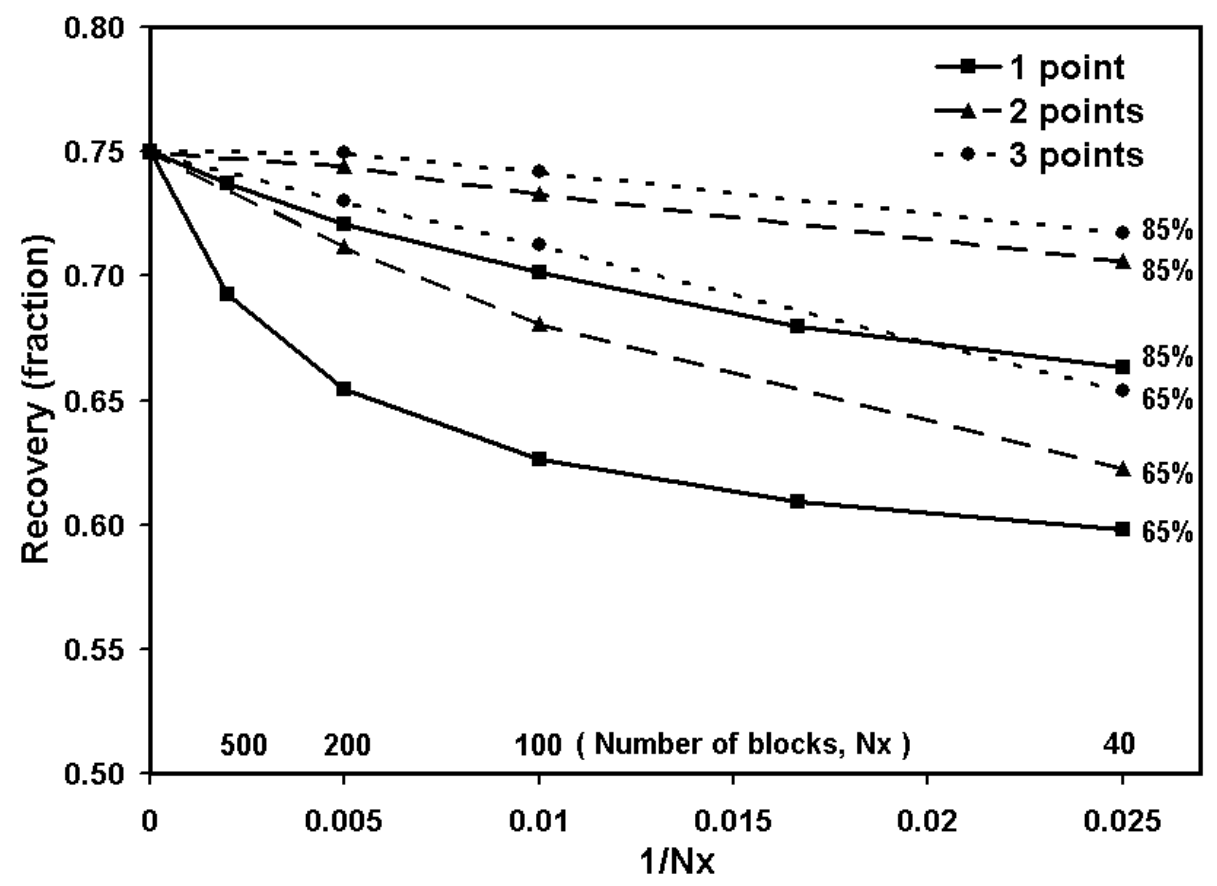

Figure 1.1--Oil recovery at 1.2 HCPVI for the 1-D homogeneous model. A slug solvent of $0.2 \mathrm{HCPV}$ displaces the oil. Both enrichments are above the MME of 60 percent. 


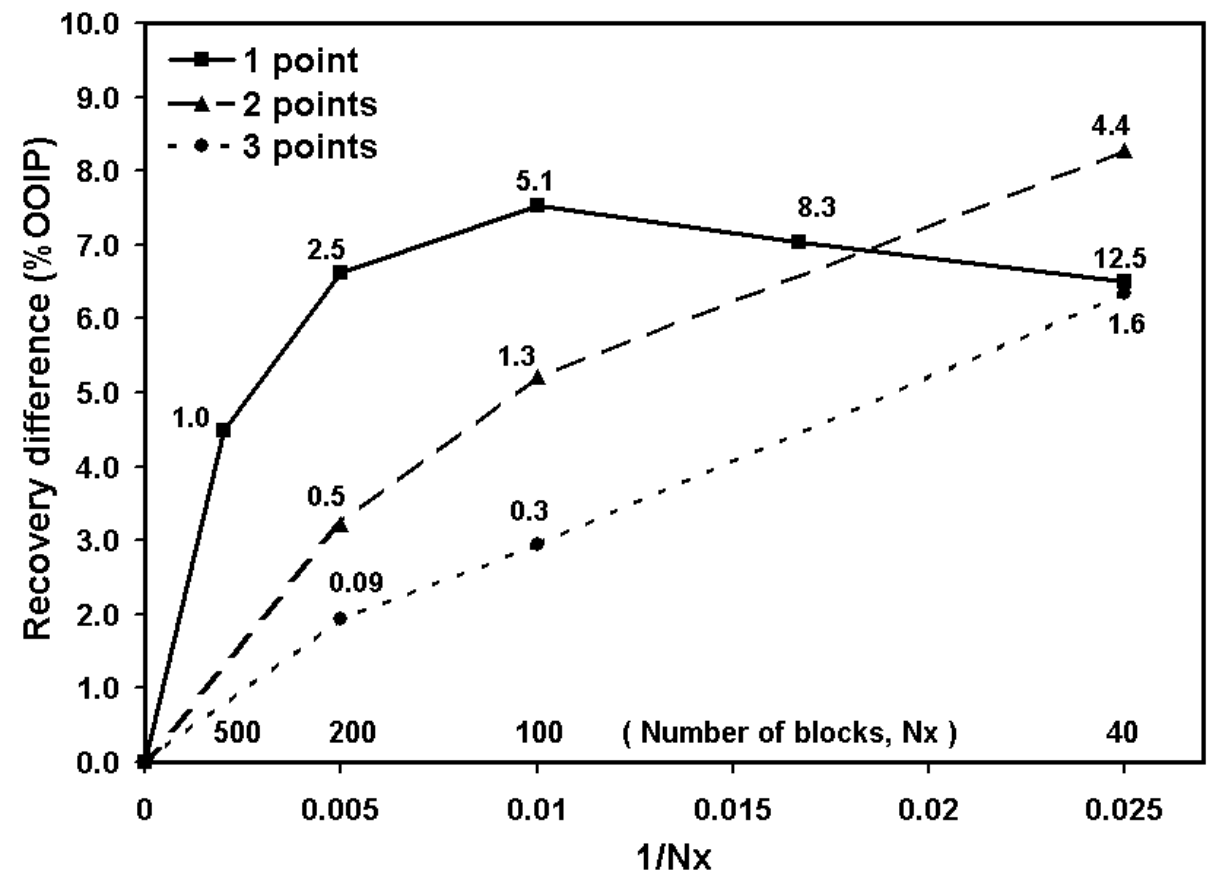

Figure 1.2--Difference in recovery between 85 and 65 percent solvent slugs at 1.2 HCPVI for the 1-D homogeneous model. Values for effective dispersivity are shown. 


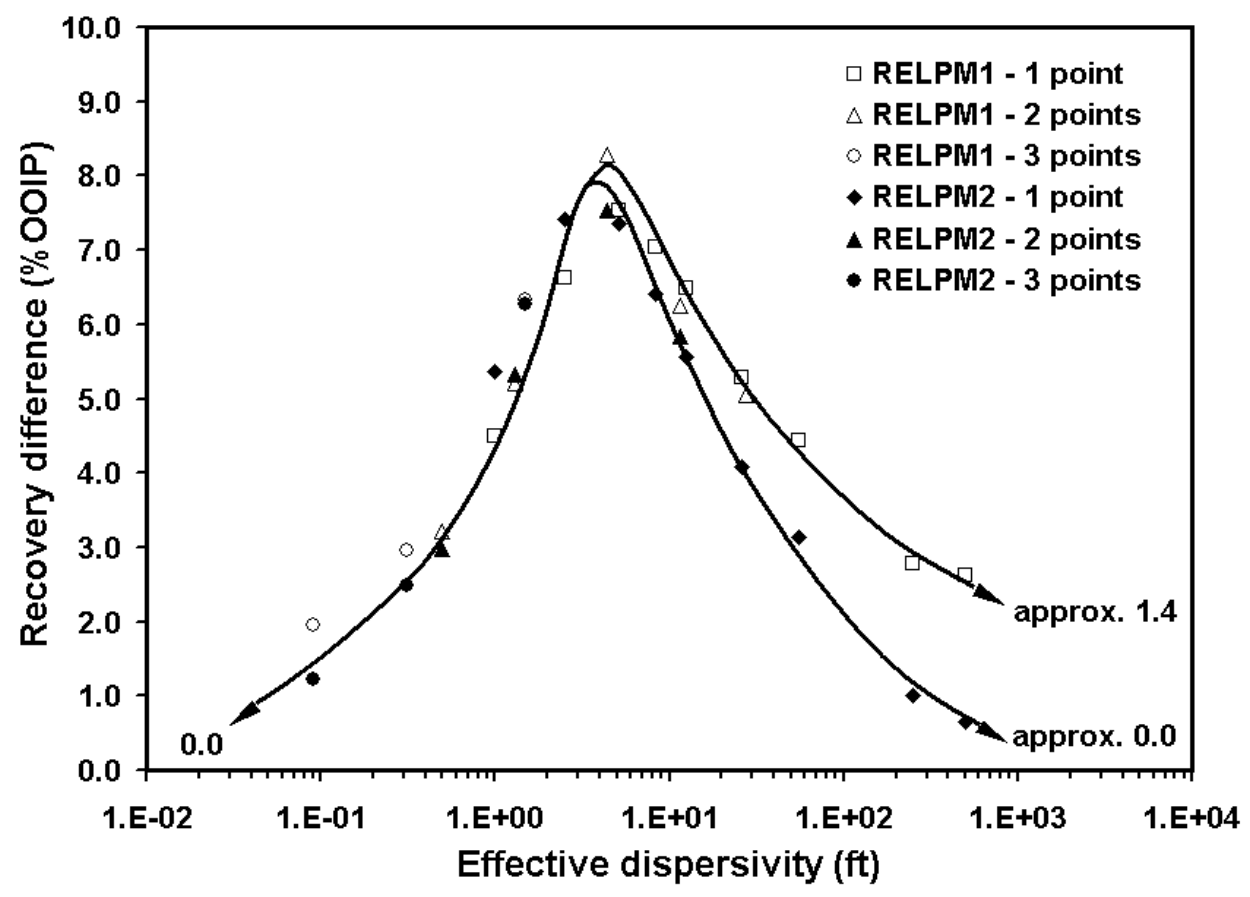

Figure 1.3--Recovery difference between 85 and 65 percent solvent slug for 1-D homogeneous model. The trends show nearly log normal distribution with dispersivity. At infinite dispersivity, the difference approaches 0.0 for case 1 and 1.4 for case 2. RELPM1 is a relative permeability model that includes gas trapping, whereas RELPM2 does not. 


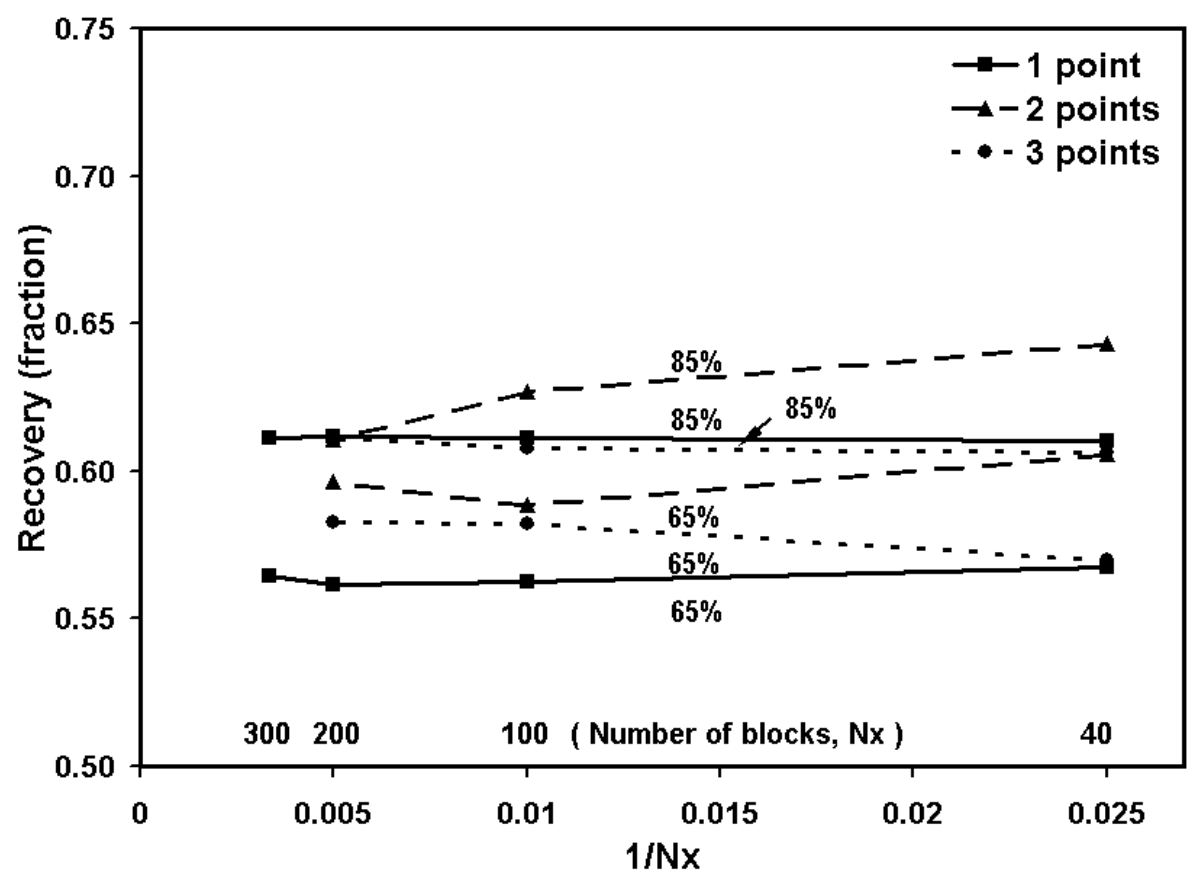

Figure 1.4--Oil recovery at 1.2 HCPVI for the 2-D homogeneous model. A slug solvent of $0.2 \mathrm{HCPV}$ displaces the oil. The effect of grid-block size on recovery is greatly reduced. 


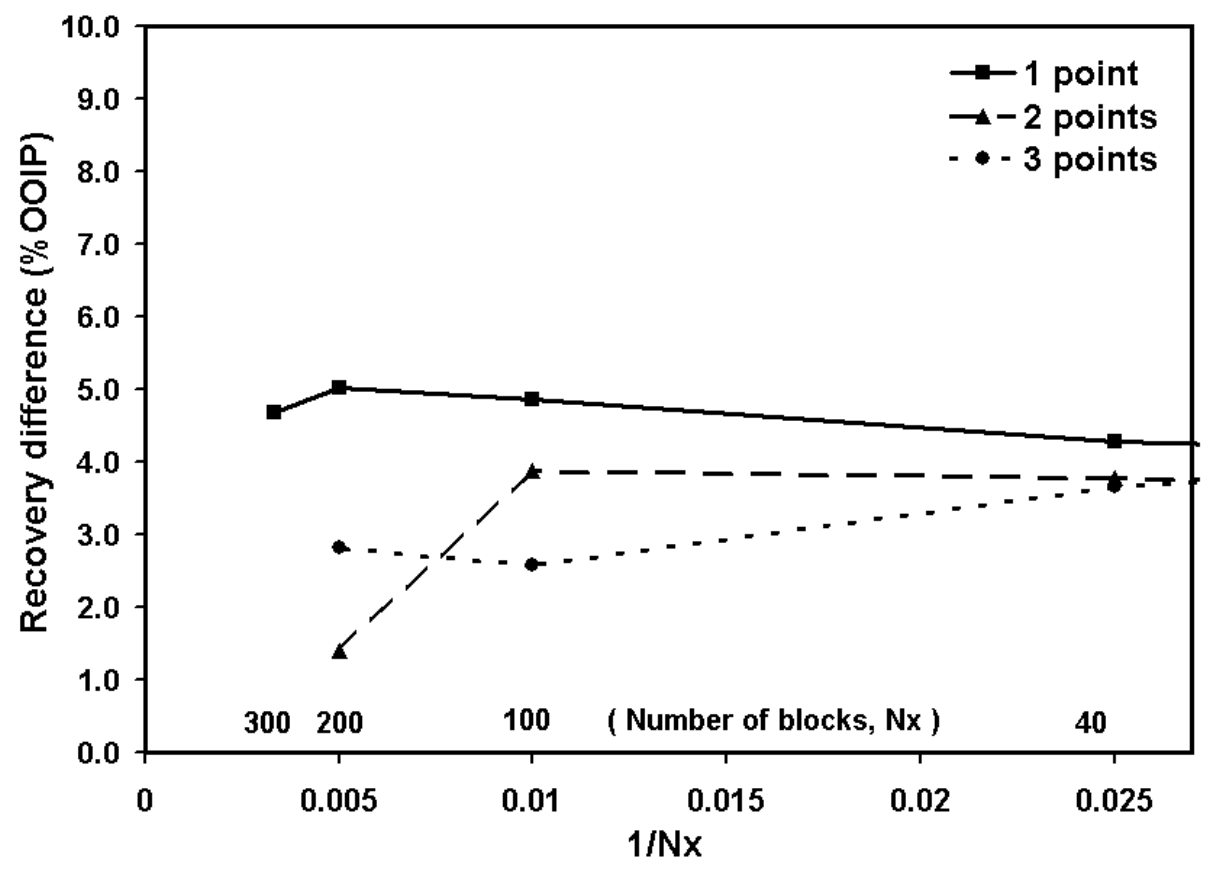

Figure 1.5--Difference in recovery between 85 and 65 percent solvent slugs at 1.2 HCPVI for the 2-D homogeneous model. 


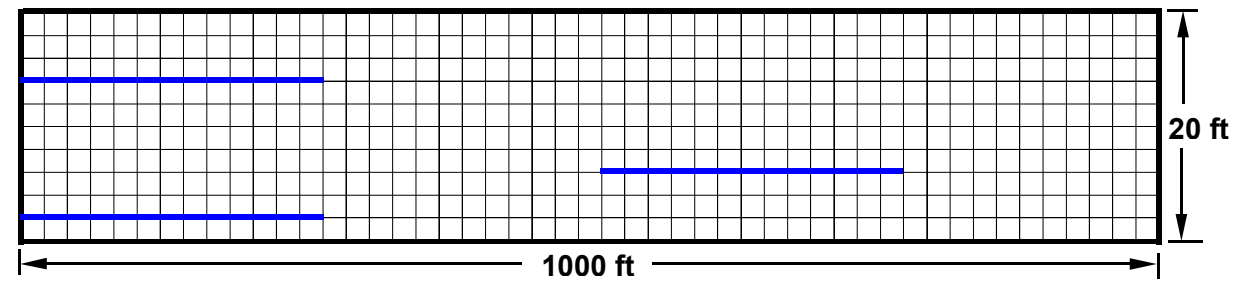

Figure 1.6-Locations of the discontinuous shales in the 2-D cross-section models. 


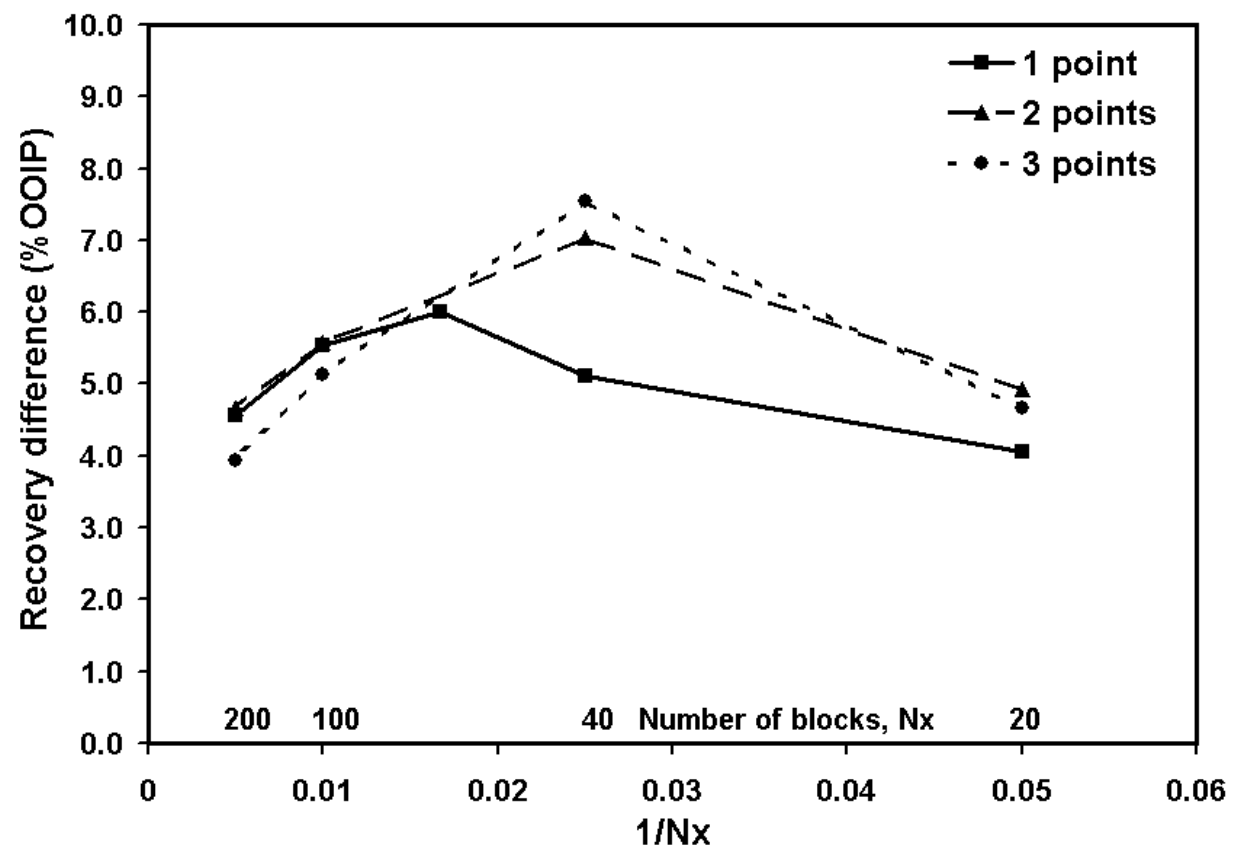

Figure 1.7--Difference in recovery between 85 and 65 percent solvent slugs at 1.2 HCPVI for the 2-D model in Fig, 11. 


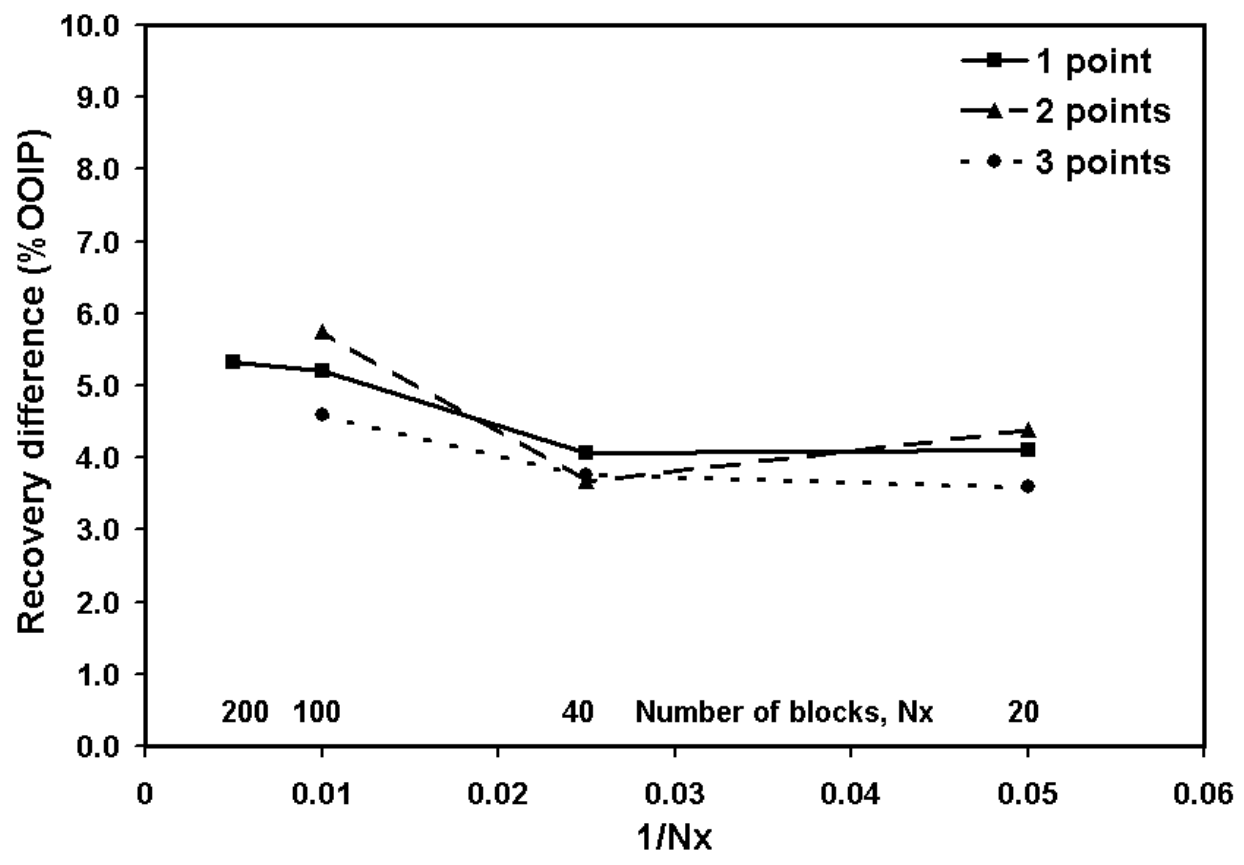

Figure 1.8--Difference in recovery between 85 and 65 percent solvent WAG at 1.2 HCPVI for the 2-D model with shales. 


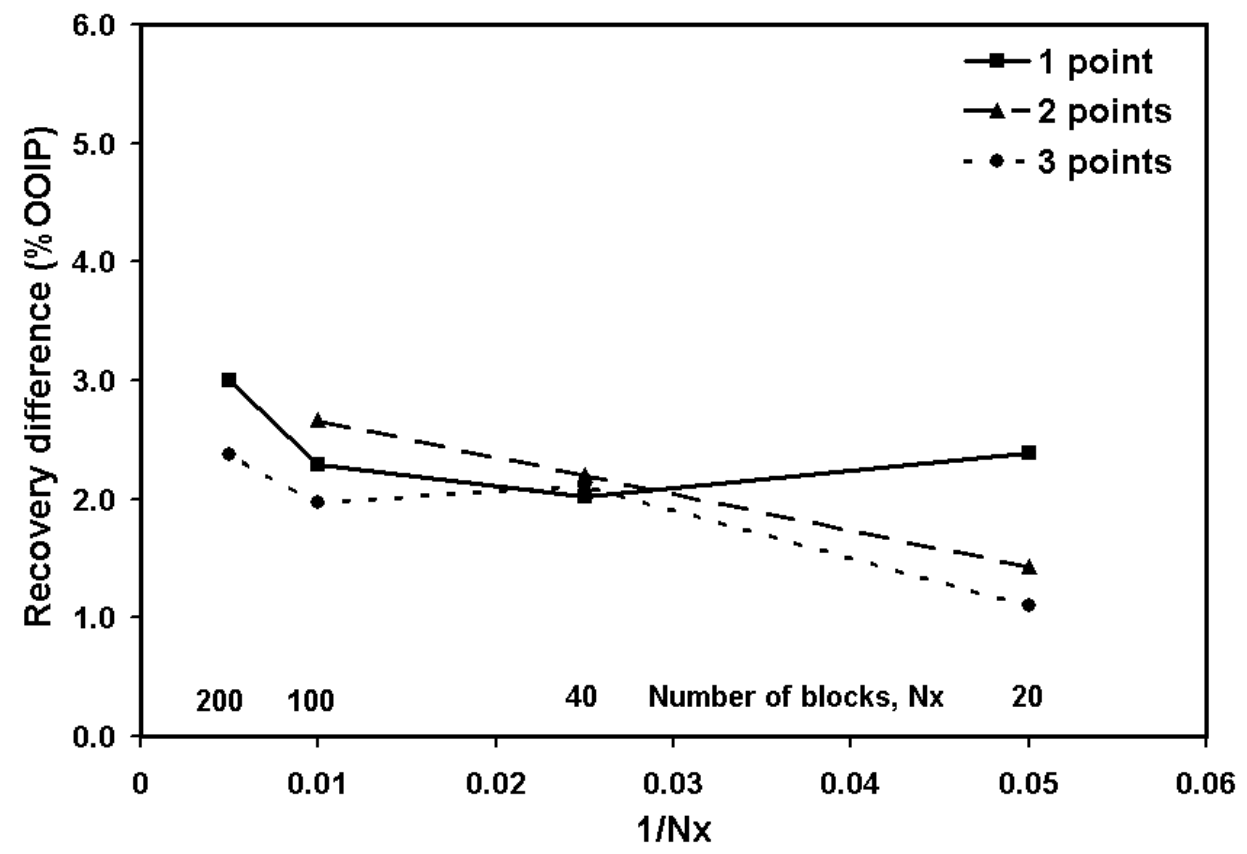

Figure 1.9--Difference in recovery between 85 and 65 percent solvent WAG at 1.2 HCPVI for the 2-D layered model. 


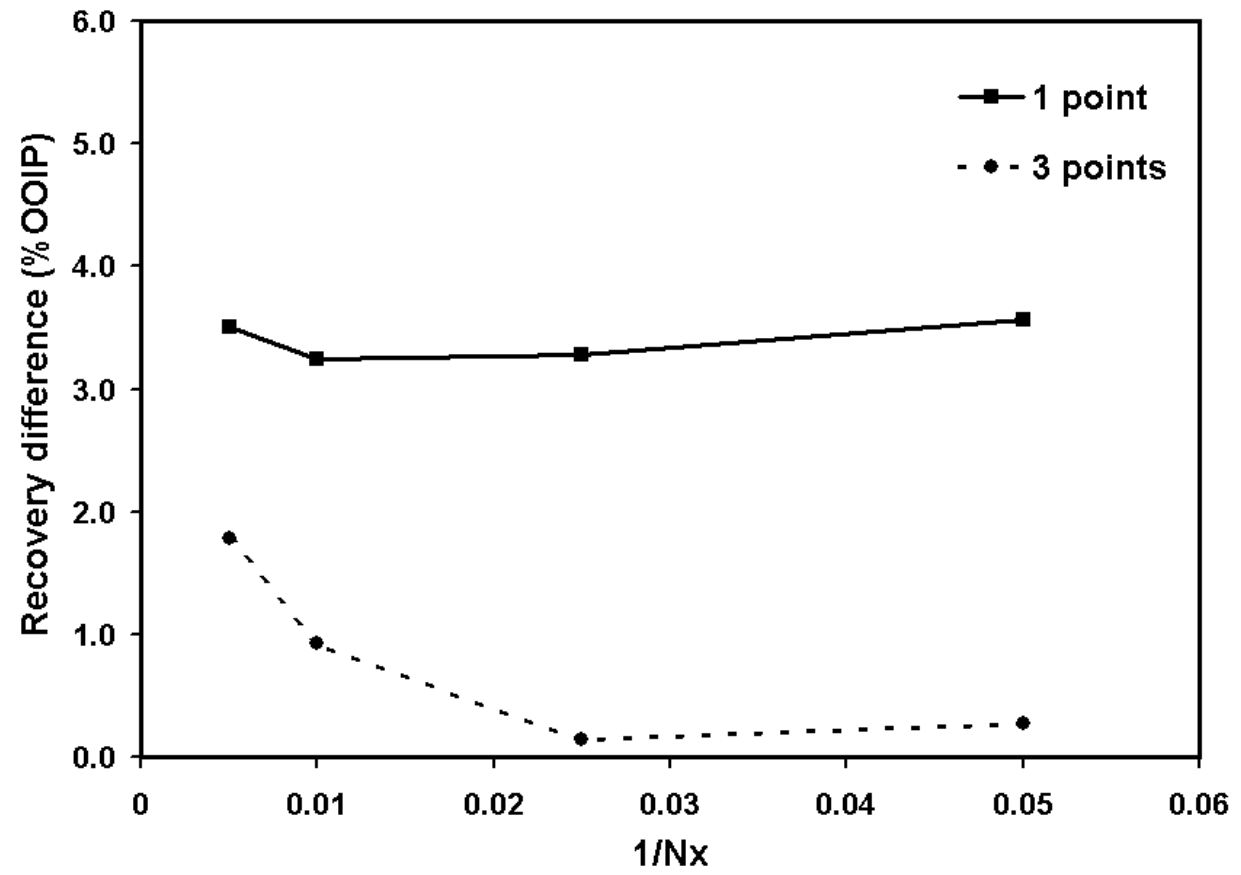

Figure 1.10--Difference in recovery between 85 and 65 percent solvent slug at $1.2 \mathrm{HCPVI}$ for the 2-D layered model. 
1 point - $65 \%$ enrichm ent

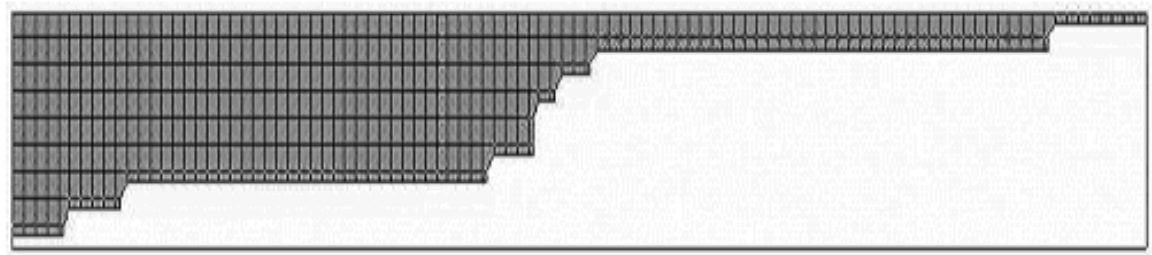

1 point $-85 \%$ enrichm ent

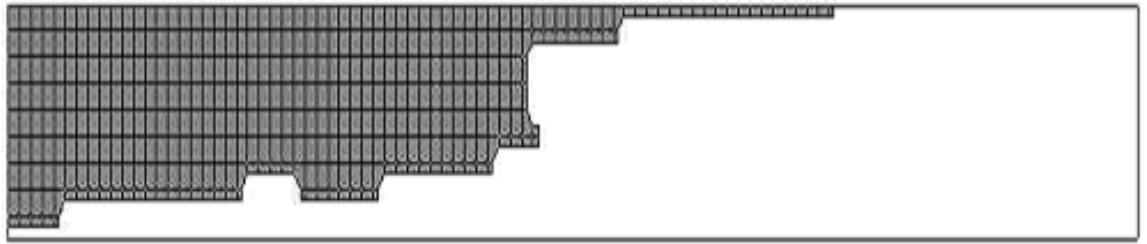

3 points $-65 \%$ enrichm ent

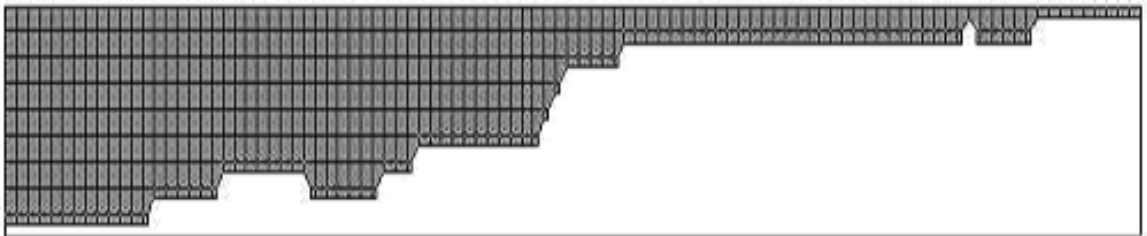

3 points $-85 \%$ enrichment

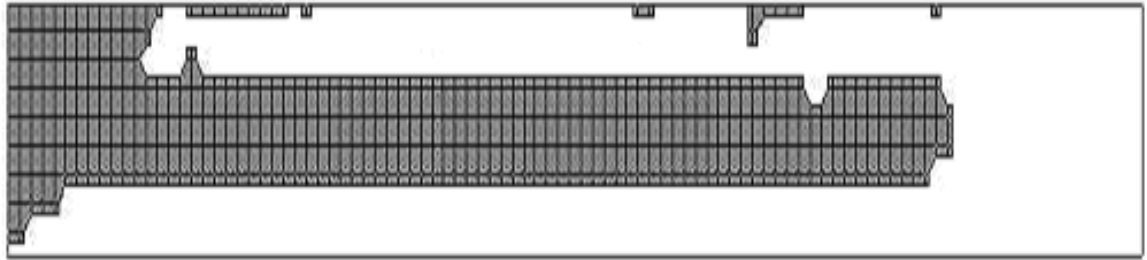

Figure 1.11--Shaded grid blocks indicate those that attained at least a maximum gas saturation of 10 percent (after 1.0 HCVPI). Gas channeling through a high permeability layer in the center of the model reduces sweep efficiency for threepoint weighting with 85 percent enriched gas. The gas channeling explains the lower recovery difference with three-point weighting in Fig. 1.10. 


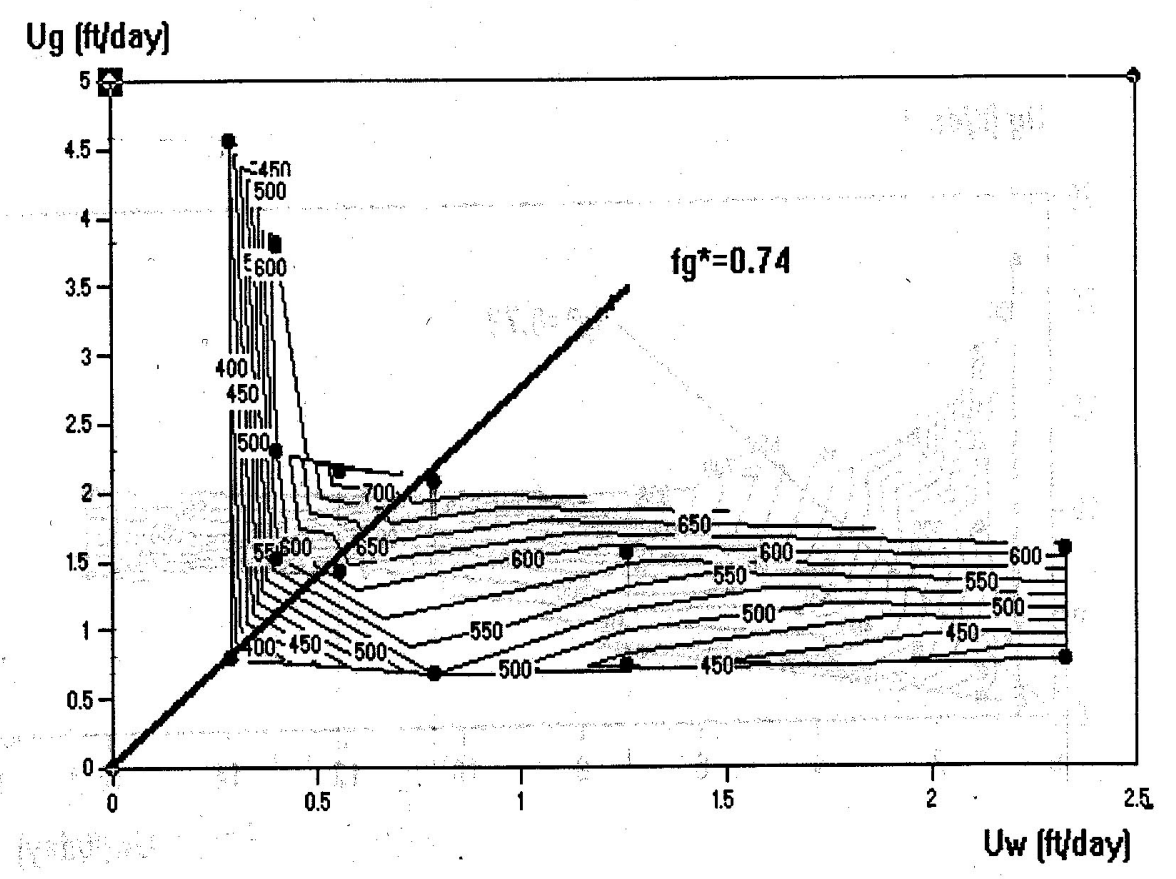

Fig. 2.1. Plot of pressure gradient ( $\mathrm{psi} / \mathrm{ft}$ ) as a function of superficial velocities of gas $\left(\mathrm{U}_{\mathrm{g}}\right)$ and water $\left(\mathrm{U}_{\mathrm{w}}\right)$ for $\mathrm{N}_{2}$ foam in Berea core; surfactant: $0.5 \mathrm{wt} \%$ of PEN-5. High-quality regime is at upper-left; low-quality regime at lower-right. Each large dot is a steady-state datum. From Alvarez et al. (2001). 


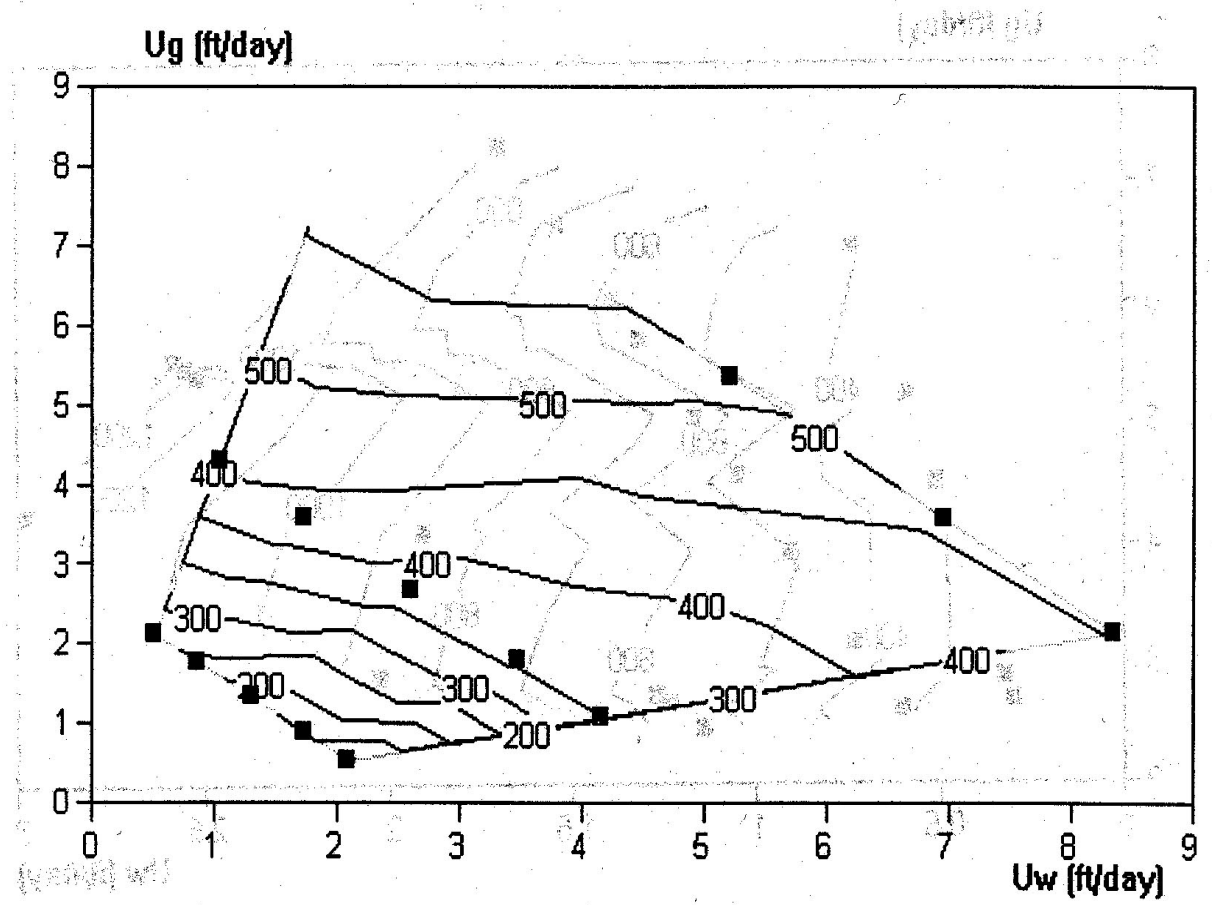

Fig. 2.2. Pressure gradient (psi/ft) as a function of superficial velocities of gas $\left(\mathrm{U}_{\mathrm{g}}\right)$ and water $\left(\mathrm{U}_{\mathrm{w}}\right)$ for supercritical $\mathrm{CO}_{2}$ foam based on data from Chang and Grigg (1998) for Berea core with permeability $=140 \mathrm{md}$, at relatively low foam quality. Each large dot is a steady-state datum. 


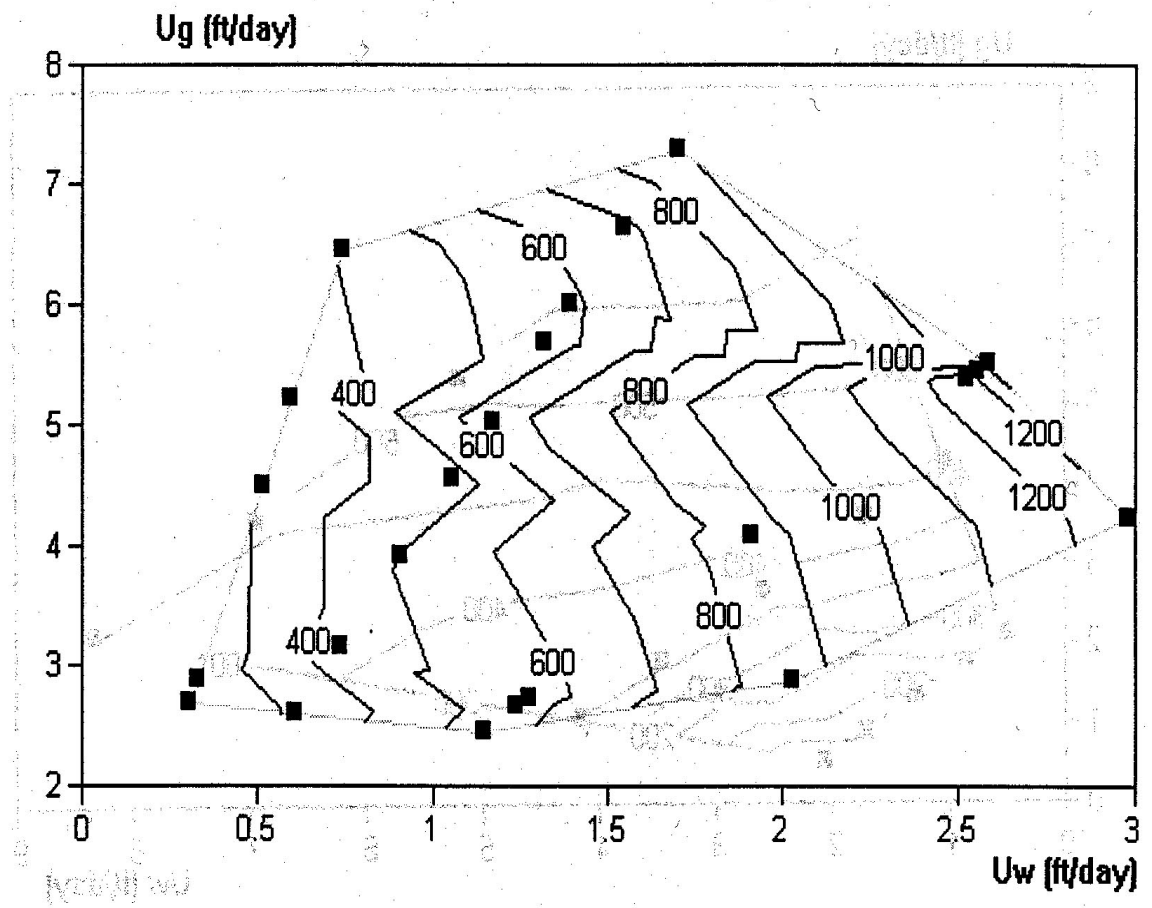

Fig. 2.3. Pressure gradient (psi/ft) as a function of superficial velocities of gas $\left(\mathrm{U}_{\mathrm{g}}\right)$ and water $\left(\mathrm{U}_{\mathrm{w}}\right)$ for supercritical $\mathrm{CO}_{2}$ foam) based on data from Lee and Heller (1990); Berea core with permeability $=308 \mathrm{md}$, at relatively high foam quality. Each large dot is a steady-state datum. 


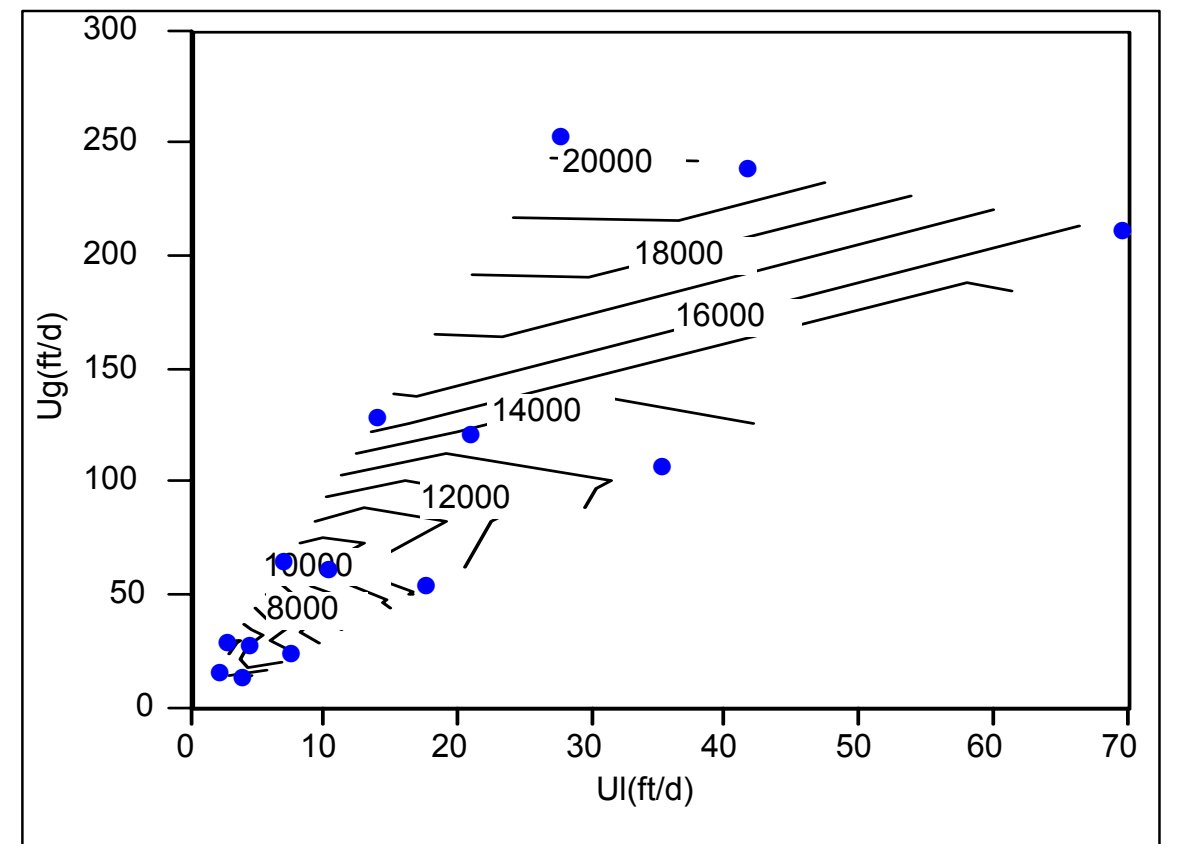

Fig. 2.4. Pressure gradient (psi/ft) as a function of superficial velocities of gas $\left(\mathrm{U}_{\mathrm{g}}\right)$ and liquid $\left(\mathrm{U}_{1}\right)$ for supercritical $\mathrm{CO}_{2}$ foam based on data from Heller et al. (1985); relatively low foam quality. Each large dot is a steady-state datum. 


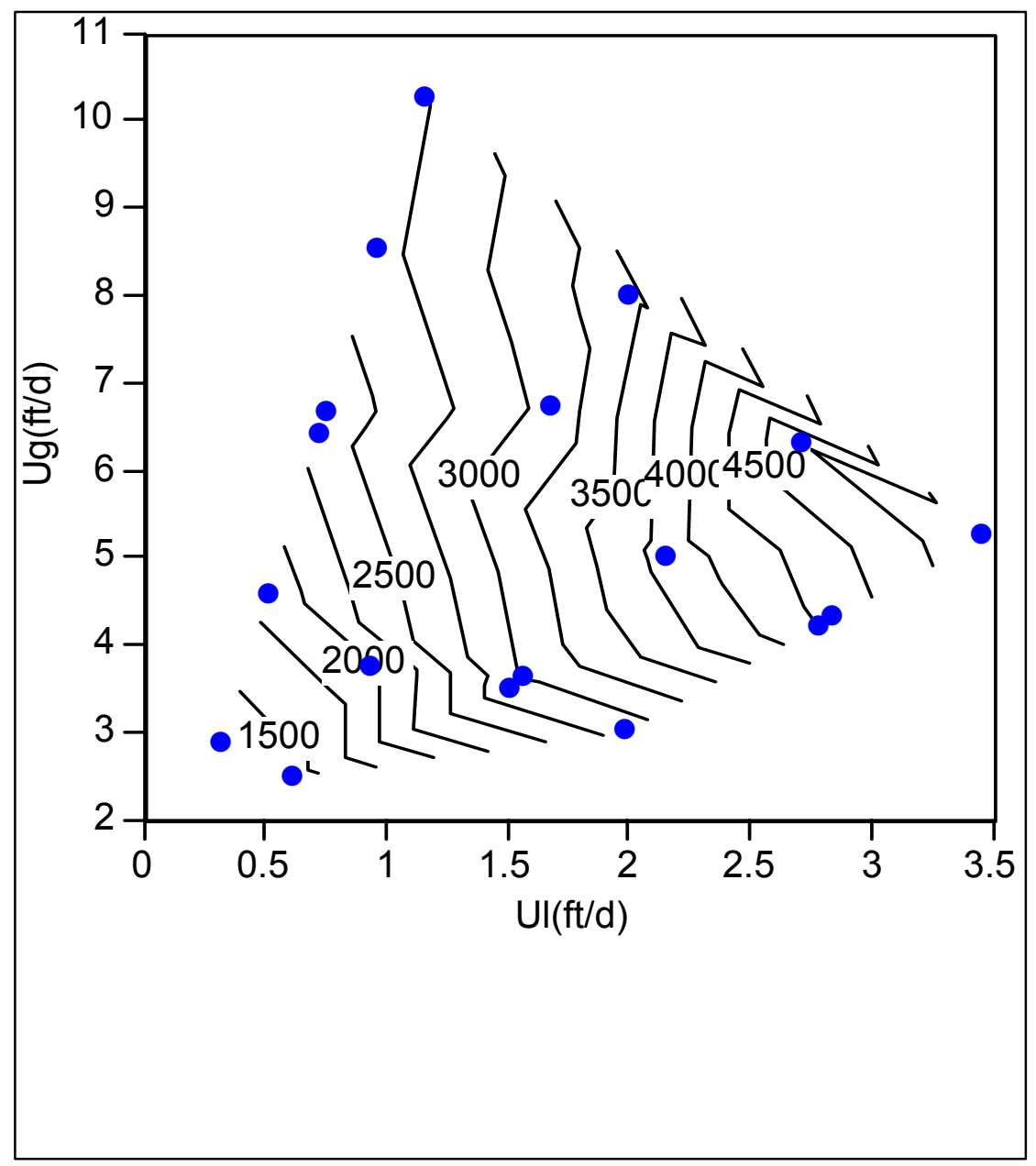

Fig. 2.5. Pressure gradient (psi/ft) as a function of superficial velocities of gas $\left(U_{g}\right)$ and liquid $\left(\mathrm{U}_{1}\right)$ for supercritical $\mathrm{CO}_{2}$ foam based on data from Lee and Heller (1989); relatively high foam quality. Each large dot is a steady-state datum. 


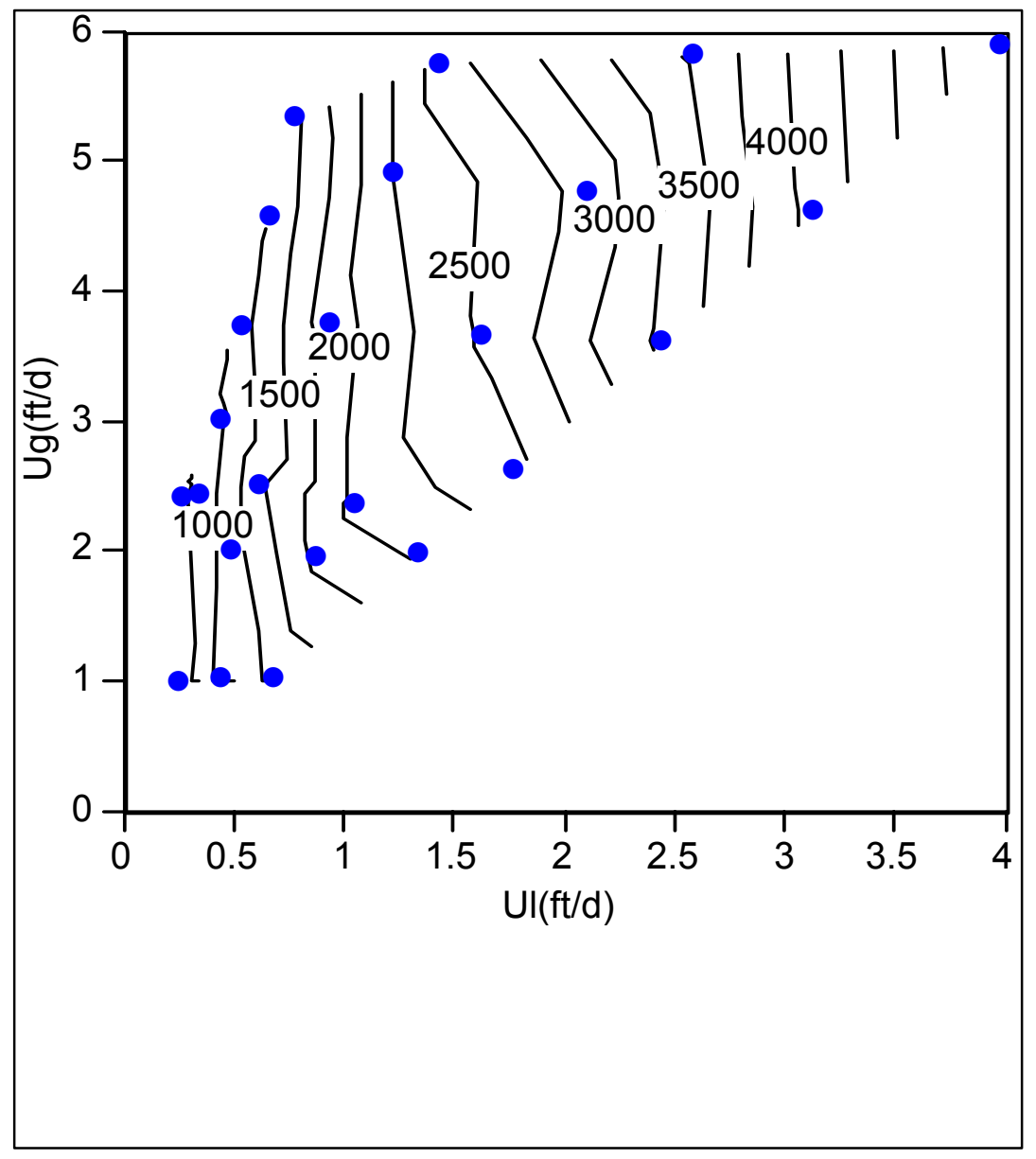

Fig. 2.6. Pressure gradient (psi/ft) as a function of superficial velocities of gas $\left(\mathrm{U}_{\mathrm{g}}\right)$ and liquid $\left(\mathrm{U}_{1}\right)$ for supercritical $\mathrm{CO}_{2}$ foam based on data from Lee and Heller (1989); relatively low foam quality. Each large dot is a steady-state datum. 


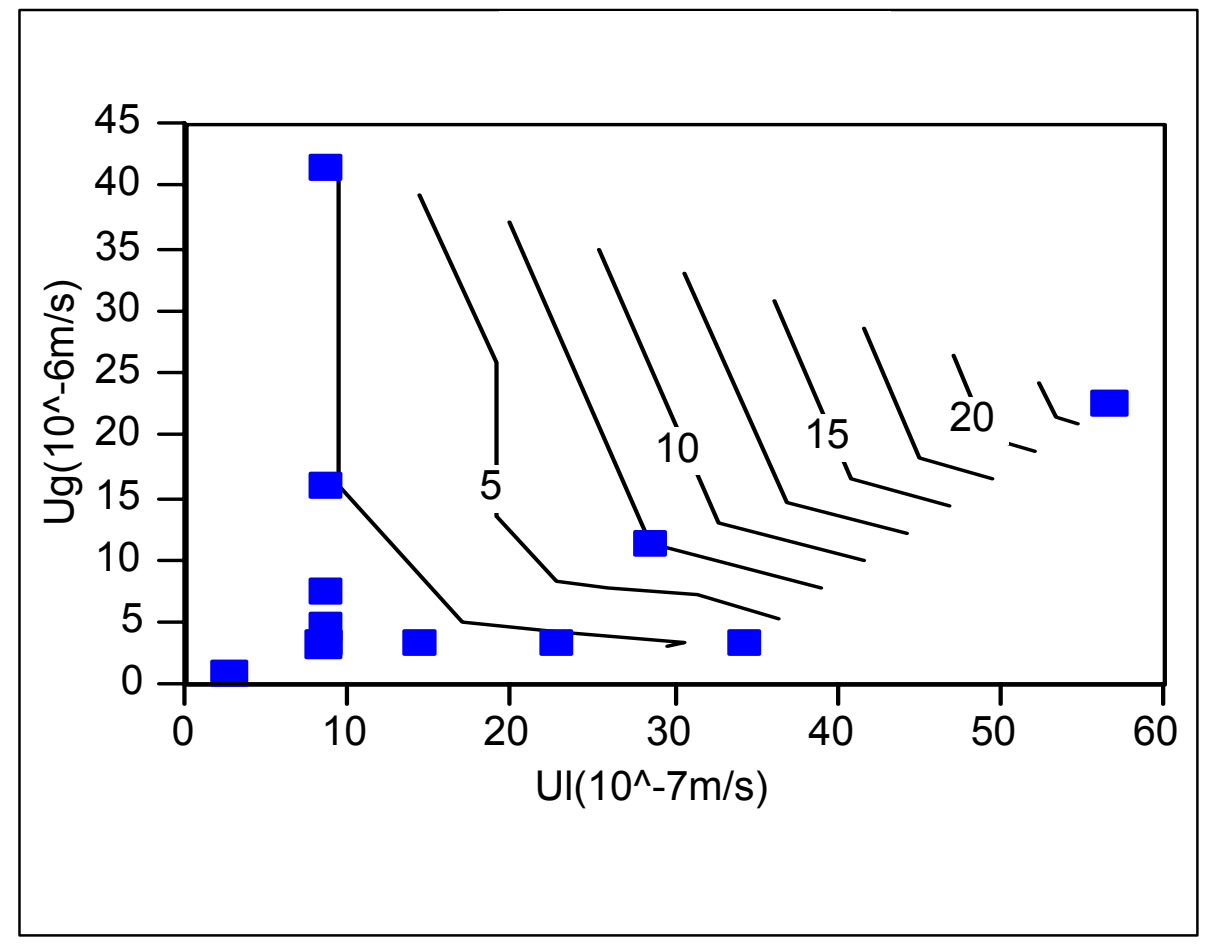

Fig. 2.7. Pressure gradient (psi/ft) as a function of superficial velocities of gas $\left(\mathrm{U}_{\mathrm{g}}\right)$ and liquid $\left(\mathrm{U}_{1}\right)$ for supercritical $\mathrm{CO}_{2}$ foam based on data from Yaghoobi and Heller (1994); surfactant: CD1050; relatively high foam quality. Each large dot is a steady-state datum. 


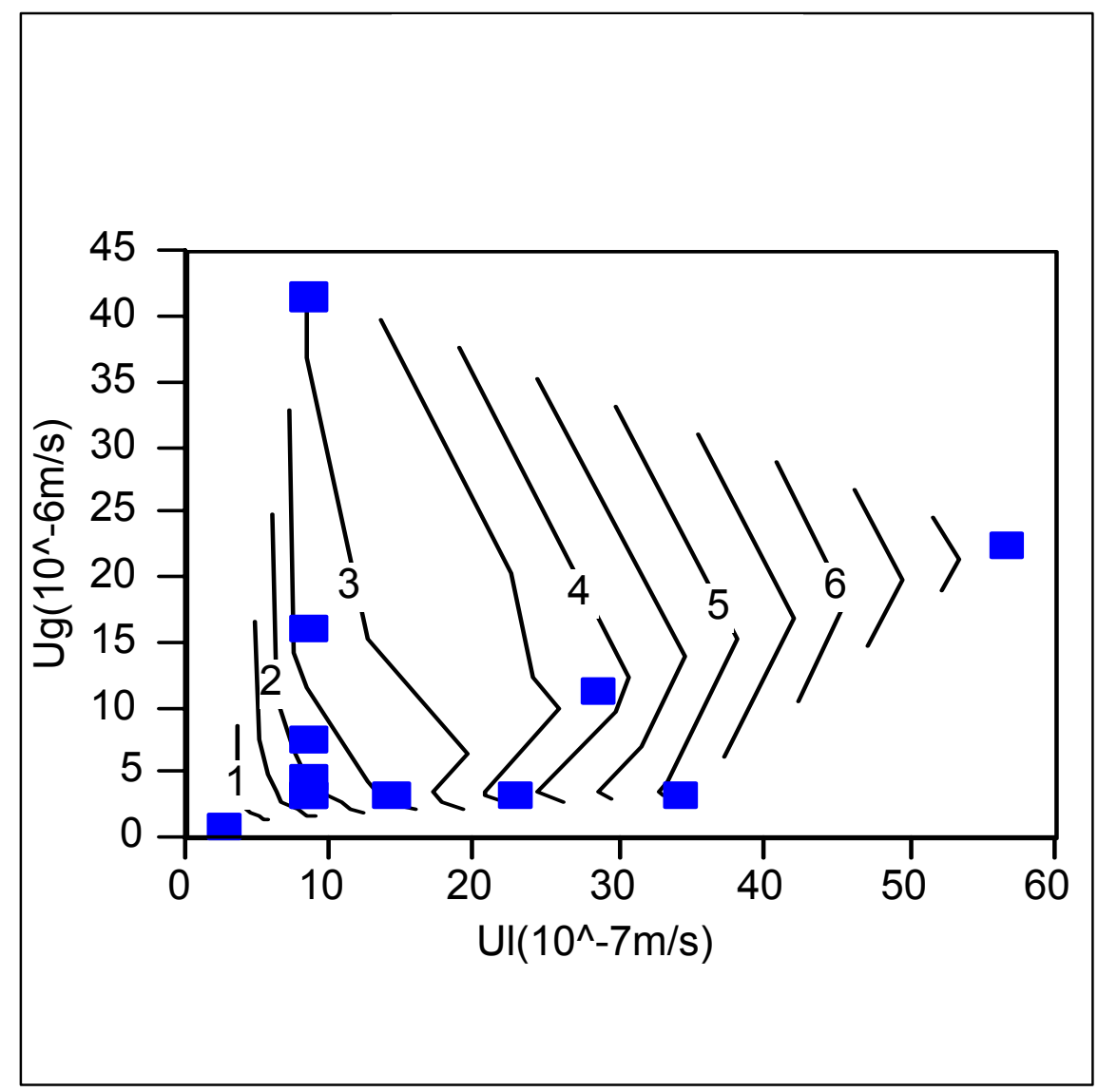

Fig. 2.8. Pressure gradient (psi/ft) as a function of superficial velocities of gas $\left(\mathrm{U}_{\mathrm{g}}\right)$ and liquid $\left(\mathrm{U}_{1}\right)$ for supercritical $\mathrm{CO}_{2}$ foam based on data from Yaghoobi and Heller (1994); surfactant: CD1040; relatively high foam quality. Each large dot is a steady-state datum. 


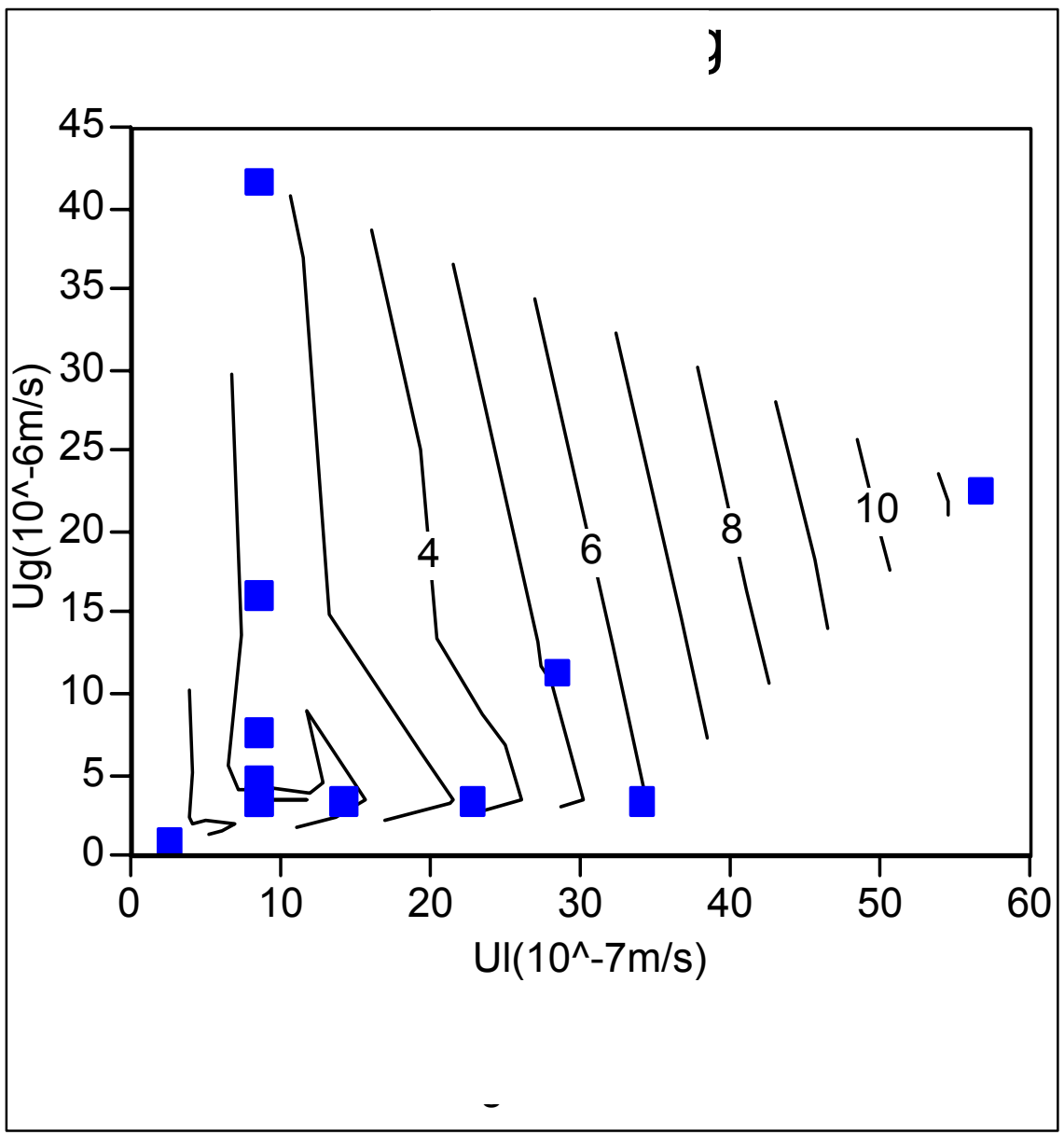

Fig. 2.9. Pressure gradient (psi/ft) as a function of superficial velocities of gas $\left(\mathrm{U}_{\mathrm{g}}\right)$ and liquid $\left(\mathrm{U}_{1}\right)$ for supercritical $\mathrm{CO}_{2}$ foam based on data from Yaghoobi and Heller (1994); surfactant: Enordet; relatively high foam quality. Each large dot is a steady-state datum. 


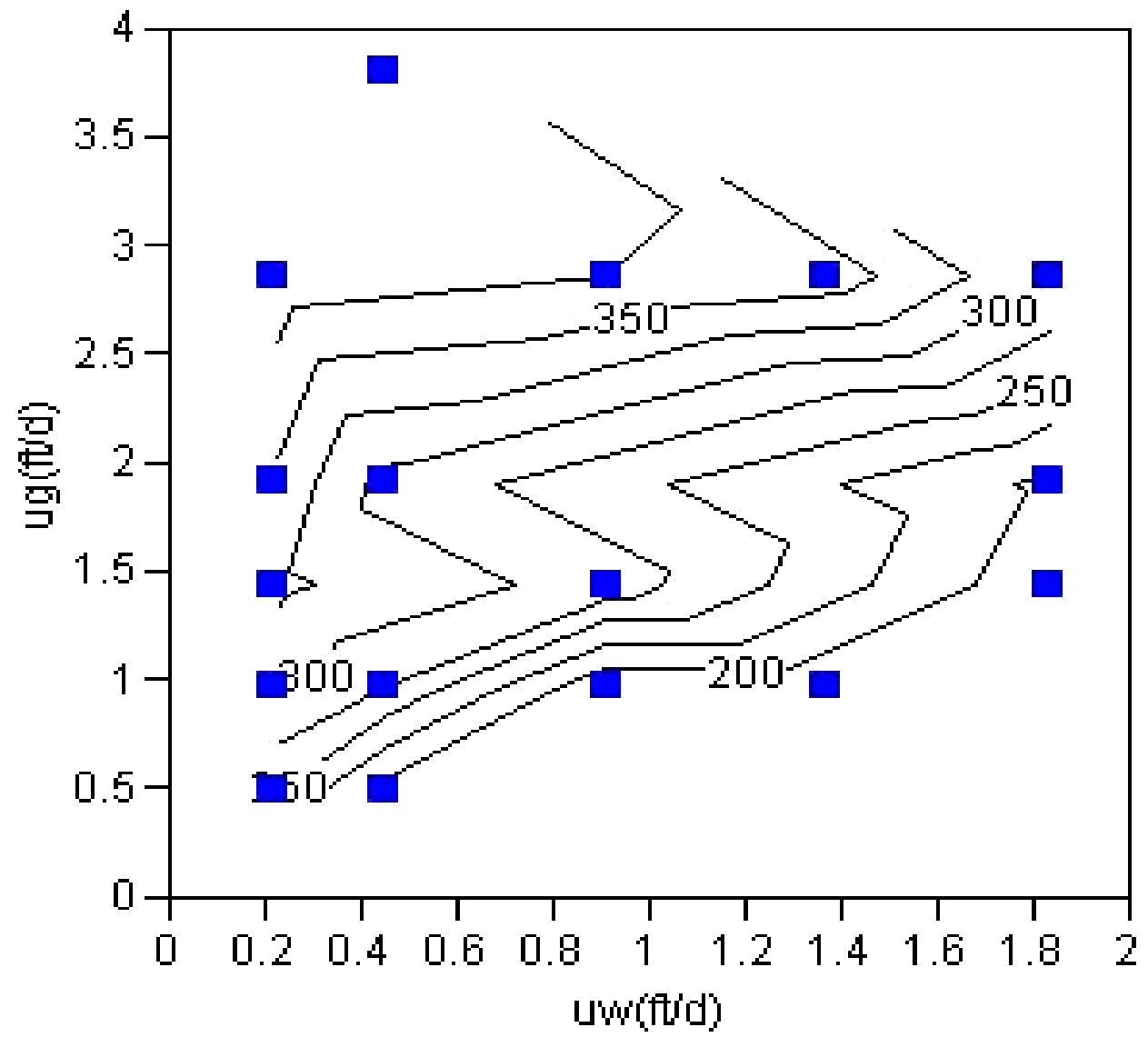

Fig. 2.10. Pressure gradient in $\mathrm{psi} / \mathrm{ft}$ as a function of superficial velocities of gas $\left(\mathrm{U}_{\mathrm{g}}\right)$ and liquid $\left(\mathrm{U}_{1}\right)$ for dense $\mathrm{CO}_{2}$ foam; new data, surfactant $\mathrm{CD} 1045,0.25 \mathrm{wt} \%$; Berea sandstone, $360 \mathrm{md}$. Each large dot is a steady-state datum. 


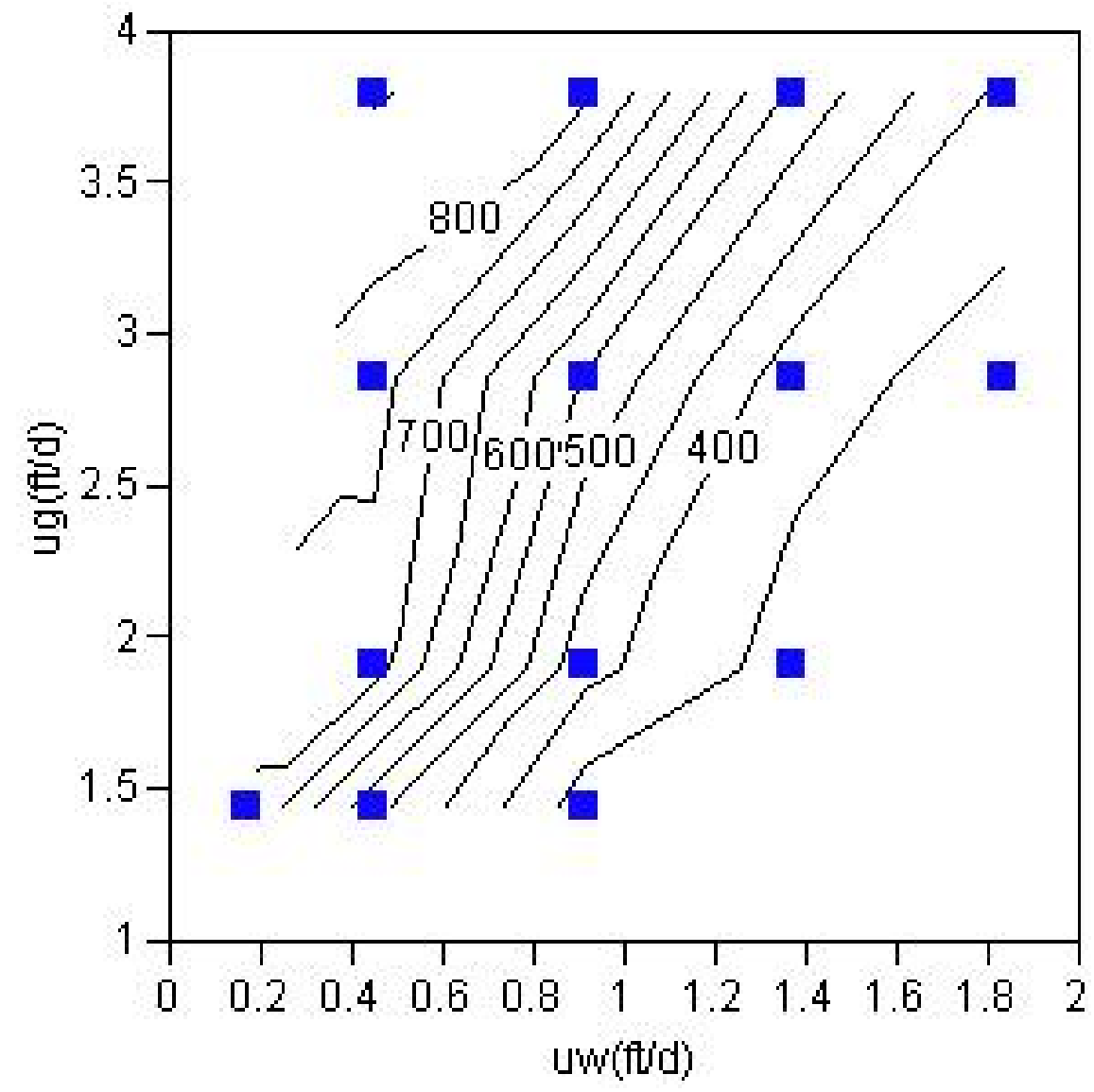

Fig. 2.11. Pressure gradient in $\mathrm{psi} / \mathrm{ft}$ as a function of superficial velocities of gas $\left(\mathrm{U}_{\mathrm{g}}\right)$ and liquid $\left(\mathrm{U}_{1}\right)$ for dense $\mathrm{CO}_{2}$ foam; new data, surfactant $\mathrm{CD} 1045$, 0.8 wt \%; Berea sandstone, $366 \mathrm{md}$. Each large dot is a steady-state datum. 


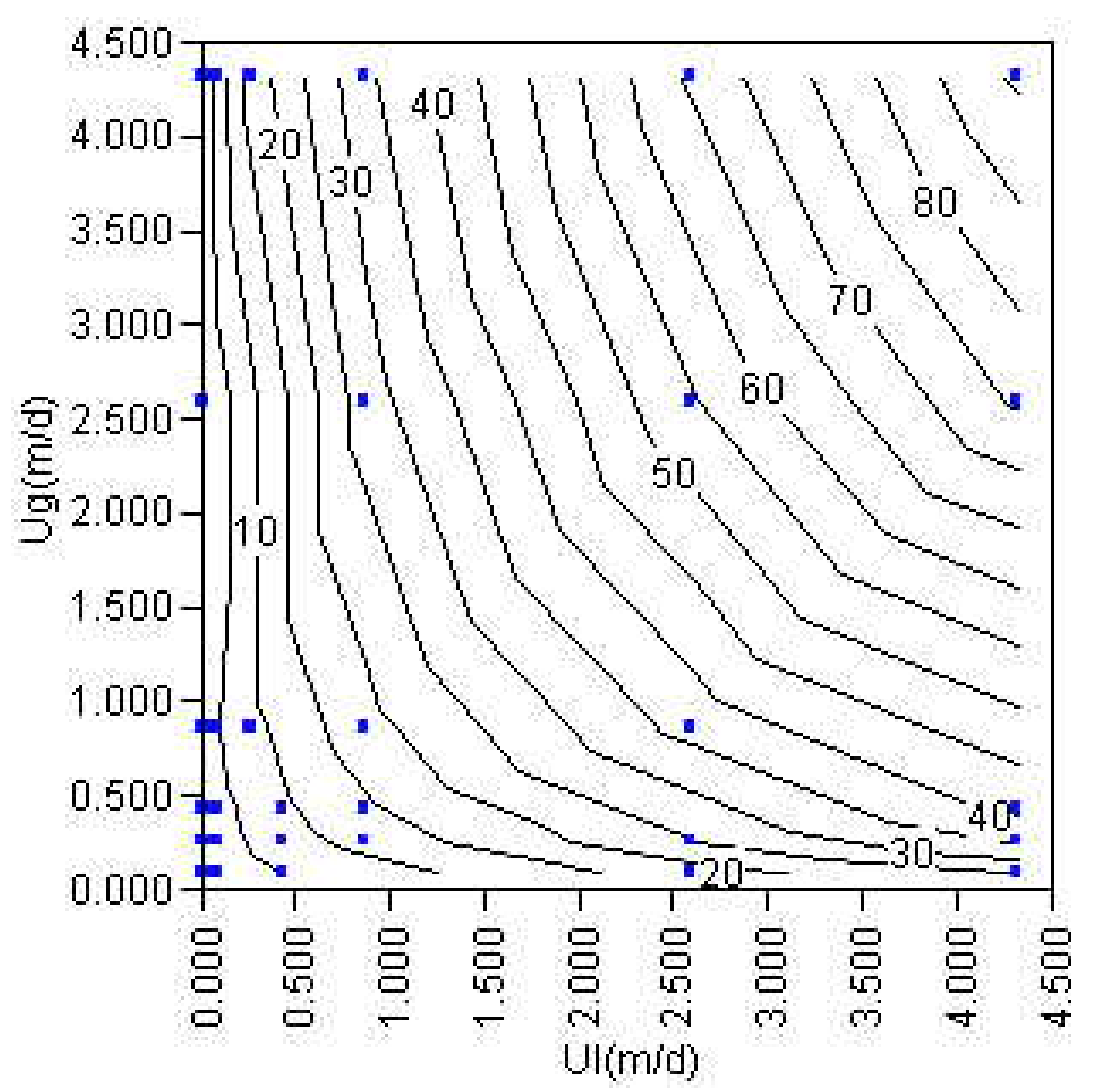

Fig. 2.12. Pressure gradient $(\mathrm{MPa} / \mathrm{m})$ as a function of superficial velocities of gas $\left(\mathrm{U}_{\mathrm{g}}\right)$ and liquid $\left(\mathrm{U}_{1}\right)$ based on foam model of Vassenden and Holt (2000). Large dots here are merely points selected for constructing contours 


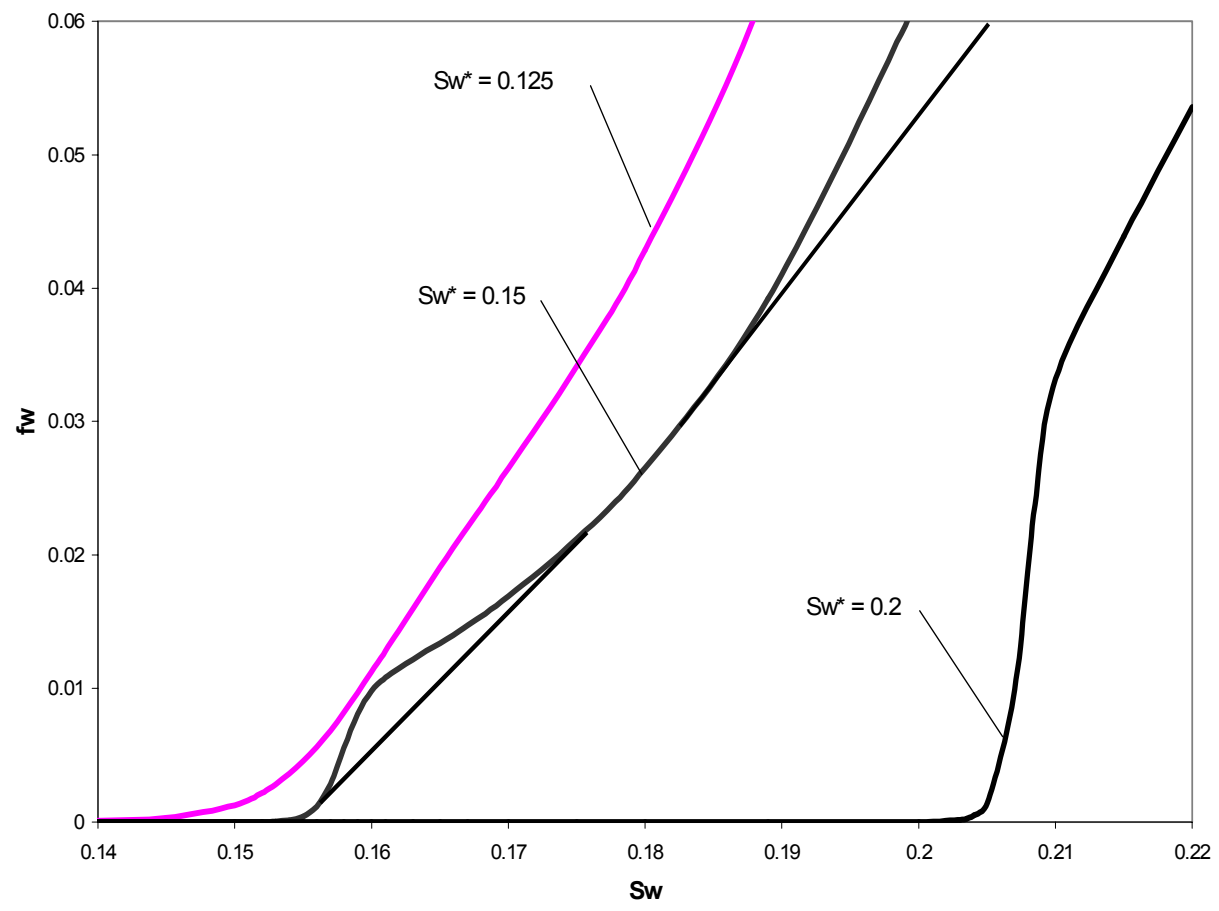

Fig. 2.12. Fractional-flow curves based on foam model of Vassenden and Holt (2000) for three values of model parameter $\mathrm{S}_{\mathrm{w}}{ }^{*}$. The shock front in a SAG process is shown for $\mathrm{S}_{\mathrm{W}}{ }^{*}=0.15$. In all three cases the fractional-flow curve is rounded at the lowest values of $f_{w}$. 


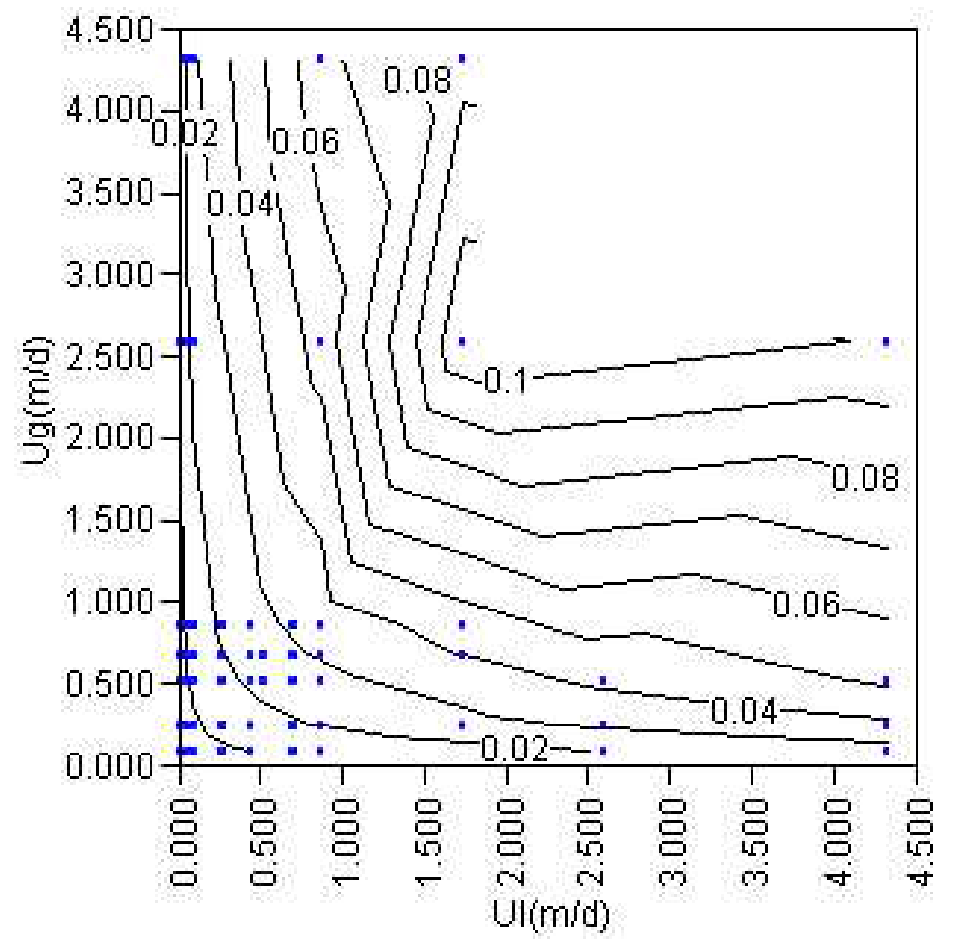

Fig. 2.14. Pressure gradient $(\mathrm{MPa} / \mathrm{m})$ as a function of superficial velocities of gas $\left(\mathrm{U}_{\mathrm{g}}\right)$ and liquid $\left(\mathrm{U}_{1}\right)$ based on foam model of Bertin (2000). Large dots are here merely points selected for constructing contours 


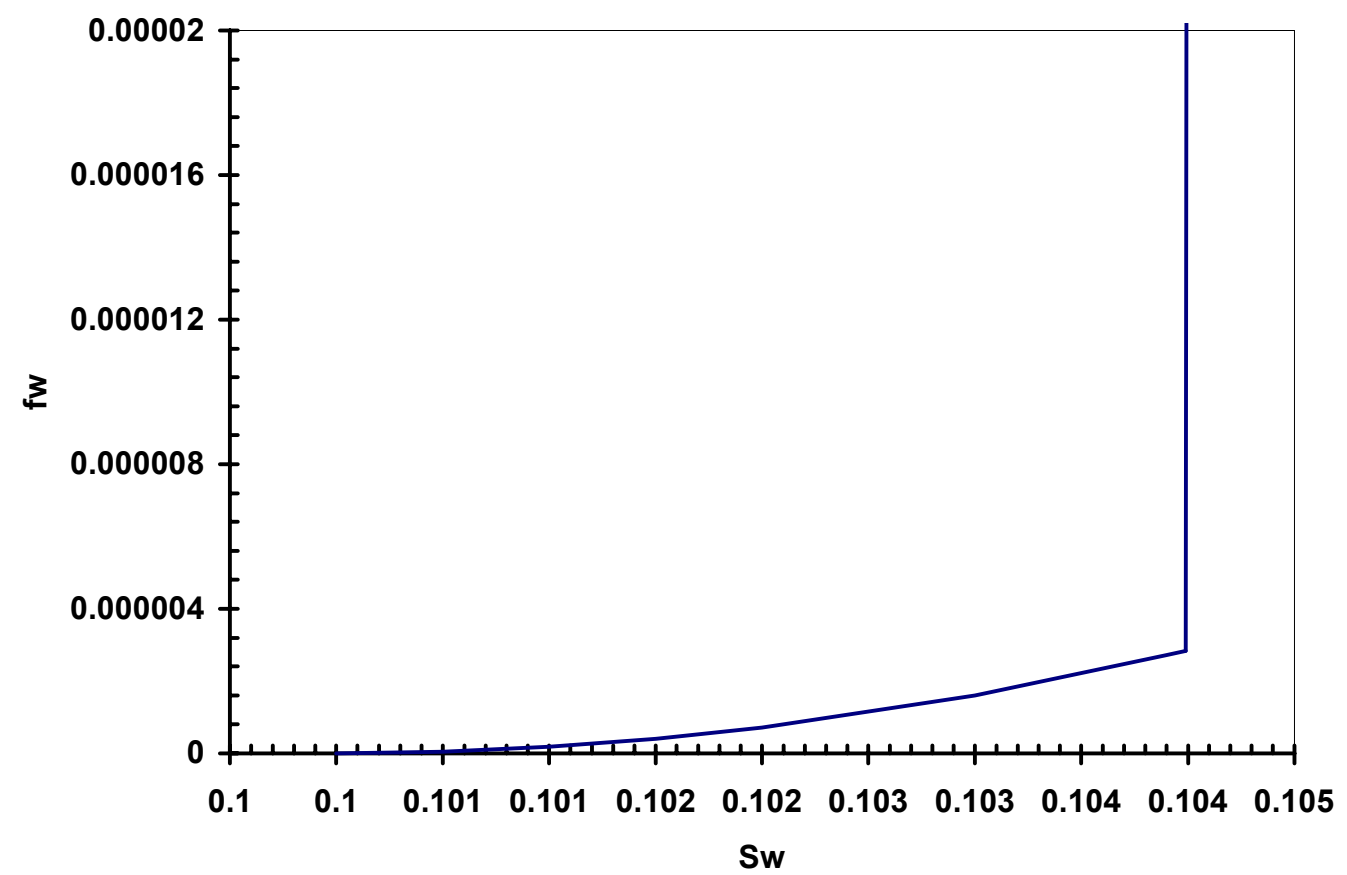

Fig. 2.14. Expanded view of fractional-flow curve based on foam model of Bertin (2000). The fractional-flow curve has a corner at low $f_{w}$, which suggests in a SAG process foam would form and collapse within a shock front of negligible width. 